\title{
A systematic review of economic evaluations in non-insulin antidiabetic treatments for patients with type 2 diabetes mellitus
}

Global \& Regional Health Technology

Assessment

Volume 2019: 1-26

(C) The Author(s) 2019

Article reuse guidelines: sagepub.com/journals-permissions DOI: 10.1 | 777/2284240319876574 journals.sagepub.com/home/grh @SAGE

\author{
Néboa Zozaya ${ }^{1,2}$ (D), Margarita Capel ${ }^{3}$, \\ Susana Simón ${ }^{3}$ and Alfonso Soto-González ${ }^{4}$
}

\begin{abstract}
The approval of new non-insulin treatments has broadened the therapeutic arsenal, but it has also increased the complexity of choice for the treatment of type 2 diabetes mellitus (DM2). The objective of this study was to systematically review the literature on economic evaluations associated with non-insulin antidiabetic drugs (NIADs) for DM2. We searched in Medline, IBECS, Doyma and SciELO databases for full economic evaluations of NIADs in adults with DM2 applied after the failure of the first line of pharmacological treatment, published between 2010 and 20I7, focusing on studies that incorporated quality-adjusted life years (QALYs). The review included a total of 57 studies, in which I 34 comparisons were made between NIADs. Under an acceptability threshold of 25,000 euros per QALY gained, iSLGT-2 were preferable to iDPP-4 and sulfonylureas in terms of incremental cost-utility. By contrast, there were no conclusive comparative results for the other two new NIAD groups (GLP-I and iDPP-4). The heterogeneity of the studies' methodologies and results hindered our ability to determine under what specific clinical assumptions some NIADs would be more cost-effective than others. Economic evaluations of healthcare should be used as part of the decision-making process, so multifactorial therapeutic management strategies should be established based on the patients' clinical characteristics and preferences as principal criteria.
\end{abstract}

\section{Keywords}

Economic evaluation, diabetes mellitus, systematic review, non-insulin antidiabetic treatments

Date received: 8 April 2019; accepted: 26 August 2019

\section{Introduction}

Diabetes mellitus type 2 (DM2) is one of the chronic diseases with the greatest impact on public health in developed countries, due to its high prevalence and associated morbidity and mortality. ${ }^{1}$ It is estimated that diabetes accounts for $11.6 \%$ of total healthcare expenditure worldwide and for $8.2 \%$ of public health expenditure in Spain. ${ }^{2,3}$
'Department of Health Economics, Weber Economía y Salud, Madrid, Spain

2University of Las Palmas de Gran Canaria, Las Palmas, Spain

${ }^{3}$ Astrazéneca, Madrid, Spain

${ }^{4}$ Department of Endocrinology and Nutrition, Gerencia de Gestión Integrada de A Coruña, A Coruña, Spain

Corresponding author:

Néboa Zozaya, Department of Health Economics, Weber Economía y Salud, C/ Moreto, 17, Madrid 280I4, Spain.

Email: neboa.zozaya@weber.org.es 
The objectives of the treatment for DM2 are to reduce blood glucose levels to values close to normal, to prevent complications and finally to prolong survival, so adequate control of the disease is crucial. ${ }^{4}$ That is why the clinical practice guidelines recommend starting to control the glucose levels of the newly diagnosed patient with physical exercise, changes in diet and therapeutical education, unless the patients fulfil the criteria for immediate insulinisation. If after 3 months, the disease cannot be controlled, and a pharmacological treatment should be started., 5

In general, the starting drug of choice is metformin. ${ }^{5} \mathrm{In}$ cases of intolerance or contraindication, other drugs should be considered. ${ }^{7}$ When glycaemic control is not adequate in a monotherapy regimen, in general, a dual therapy would be used, combining the pharmacological treatment of two non-insulin antidiabetic drugs (NIADs), or with one insulin, assessing also different aspects of the patient and the medication in order to decide the best therapeutic option. ${ }^{6}$ The choice of the second drug should be made taking into account different aspects such as efficacy, risk of hypoglycaemia, effects on weight and other adverse effects, comorbidity, life expectancy and patient preferences, as well as the cost. Similarly, if adequate glycaemic control is not achieved under double therapy, it is recommended to start a triple therapy of NIADs in those patients who cannot or do not agree to receive insulinisation. Evaluating the different factors of the available therapeutical options is recommended to choose the most appropriate one in each case. ${ }^{6}$

The drugs to be added may be sulphonylureas, glitazones, inhibitors of dipeptidyl peptidase-4 (iDPP-4), analogues of the glucagon-like peptide 1 (aGLP-1) receptor or inhibitors of the sodium-glucose cotransporter type 2 (iSGLT-2). The most recently marketed NIADs have been the iDPP-4, aGLP-1 (since 2007) and the iSGLT-2 (since 2012). All of them achieve glycaemic control similar to that of the classic drugs, but with the additional benefit of having a lower risk of hypoglycaemia and a significant loss of weight, which often results in an improvement in patient's quality of life and a decrease in the total costs associated with the disease. ${ }^{8,9}$ However, it is necessary to analyse whether these additional clinical benefits compensate for the relatively high price of these drugs.

The introduction of new NIADs has allowed the available therapeutical arsenal to be expanded, but at the same time it has increased the complexity of choice of treatment, so it has become more difficult to know which is the optimal pharmacological intensification. ${ }^{10,11}$ Organisations such as the NICE or the American Diabetes Association have glycaemic control algorithms that try to facilitate these decisions. ${ }^{12,13}$

In the context of limited budgetary resources, prioritising the use of efficient healthcare interventions is essential for the rational use of those resources and, therefore, for the sustainability of the system. The economic evaluation is a fundamental tool for making rational decisions, which allow one to determine whether the interventions are cost-effective and whether they are worth (in terms of health) what they cost (in financial terms). Thus, with the appearance of new treatments, the economic evaluations must also be updated.

In 2009, a systematic review of economic evaluations of glucose-controlling drugs marketed in Spain was published. It concluded that all the treatments available at that time were cost-effective compared to placebo for a willingness to pay of $€ 30,000$ per year of quality-adjusted life-years (QALY) gained, with metformin being the most cost-effective treatment, so it was concluded that the second-generation oral antidiabetics should be used as a complement, and not as an alternative, to metformin. ${ }^{14}$

Just as the clinical practice guidelines need to be updated to adapt to the availability of new evidence and the development of new treatments, it is also advisable to update the mentioned report, incorporating the economic evaluations carried out recently in the field of DM2.

The main objective of this work is thus to evaluate the efficiency of NIADs in DM2, through a systematic review of the published literature about the subject. After identifying the published articles which meet the specified inclusion criteria, we compare the results obtained by the reviewed articles and assess the quality of the evidence provided. In the discussion section, the results obtained are contextualised and some considerations of interest are detailed, as well as the potential limitations of the work. Detailed information about the studies found in the review is provided in the supplementary material.

\section{Methods}

\section{Design}

To respond to the objective of the study, a systematic review of the literature was carried out in the following stages, recommended in the 'CRD's guidance for undertaking reviews in health care' of the University of York: ${ }^{15}$ (1) search of the literature, (2) selection of studies, (3) evaluation of the quality of the studies, (4) data extraction, (5) synthesis and analysis of the data, (6) preparation of the preliminary report, and (7) preparation of the final report.

\section{Search strategy}

The search strategy took into account the following terms, in both free text and controlled language (MESH terms): 'diabetes mellitus', 'DM2', 'type 2 diabetes', 'glycaemic control', 'HbAlc', 'economic evaluation', 'cost-effectiveness', 'cost-utility', 'cost-benefit', 'cost minimisation', 'costs', 'effectiveness', 'economics', 'cost-analysis' and 'QALY', 
Table I. Criteria for inclusion of the systematic review of the literature.

\begin{tabular}{ll}
\hline Full economic evaluations directly related to: & And which include: \\
\hline $\begin{array}{l}\text { Oral antidiabetic drugs for the treatment of DM2: } \\
\text { - Metformin }\end{array}$ & $\begin{array}{l}\text { A quantifiable measurement of clinical effectiveness } \\
\text { measured in terms of QALY of the alternatives } \\
\text { compared }\end{array}$ \\
$\begin{array}{l}\text { - Glinides (repaglinide) } \\
\text { - Sulphone (pioglitazone) } \\
\quad \text { gliclazide) }\end{array}$ & $\begin{array}{l}\text { A measurement of the cost of the alternatives compared } \\
\text { Incremental cost-utility ratio, or data to calculate it }\end{array}$ \\
- DPP-4 inhibitors (sitagliptin, vildagliptin, saxagliptin, & \\
- Glogliptin, linagliptin) & \\
$\quad$ albiglutide, lixisenatide) & \\
SGLT-2 inhibitors (dapagliflozin, empagliflozin, canagliflozin) & \\
\hline Limited to: & Countries: Europe, United States, Canada. \\
Patients: adults with diagnosed DM2. & Comparators: placebo, insulin or other oral/subcutaneous \\
Publication in scientific journals & non-insulin antidiabetics (in monotherapy or in combination) \\
Full-text language: Spanish, English &
\end{tabular}

DM2: diabetes mellitus type 2; DPP: dipeptidyl peptidase; SGLT: sodium-glucose cotransporter type; QALY: quality-adjusted life years; GLP: glucagon-like peptide I.

associating these terms with each of the names of the active principles under study (see Annex 1 in Supplemental material). The search strategy was conducted in January 2018.

The search strategy was launched in the following databases: Medline (through PubMed), SciELO Spain, Índice Bibliográfico Español en Ciencias de la Salud (IBECS), Doyma. The scientific evidence published in the indicated databases between January 2010 and December 2017 was reviewed, and no additional filter was applied.

\section{Inclusion criteria}

The inclusion criteria that were applied in the review of the literature are indicated in Table 1.

\section{Selection and synthesis}

The studies were initially selected by two researchers, applying the criteria for inclusion and exclusion. Two researchers carried out, in parallel, the extraction of data about the effectiveness and costs of the selected studies, entering the information into a database specifically designed for that purpose. A synthesis of the most relevant variables was carried out by a descriptive analysis which summarises the relevant information. In order to facilitate the direct comparison of the results, a conversion of the cost components was performed to express the results in euros of the year 2017, applying the official exchange rate of the year in question and the variation in the harmonised consumer price index of Spain. ${ }^{16,17}$ A maximum costeffectiveness threshold of $€ 25,000 / \mathrm{QALY}$ gained was considered, based on the implicit threshold defined for Spain. ${ }^{18}$

\section{Evaluation of the quality of the studies}

Simultaneously with the extraction of data, an evaluation of the quality of the selected studies was carried out, applying the methodology proposed by the University of York, ${ }^{15}$ and following the quality scale of Drummond, which consists of 36 items. ${ }^{19}$ Each question was evaluated, answering 'yes', 'no', 'partly', 'impossible to judge' to each of them as appropriate.

\section{Results}

\section{Search results}

The search of the literature identified a total of 601 studies. After eliminating the duplicates, the titles and abstracts of the 553 resulting articles were reviewed, from which 155 studies of potential interest were selected. After a review of their entire texts, 98 papers were excluded, for different reasons. The number of final studies included in the review amounted to 57 (Figure 1).

\section{Description of the economic evaluations included}

From the 57 studies found, 134 drug comparisons in which one of the NIADs under review was involved were extracted. Only 28 of the 57 studies required a single comparison between the two drugs. From the rest, $2(n=14), 3(n=5)$, $4(\mathrm{n}=3), 5(\mathrm{n}=1), 6(\mathrm{n}=3), 10(\mathrm{n}=1)$ and $18(\mathrm{n}=1)$ comparisons per study were extracted (Table 2). The number of comparisons extracted per study depended on the number of active substances compared, but also on other variables, such as the dose applied, the country (if results are provided for three countries, three comparisons were extracted), the time horizon, the added therapy, or the type of costs included. 


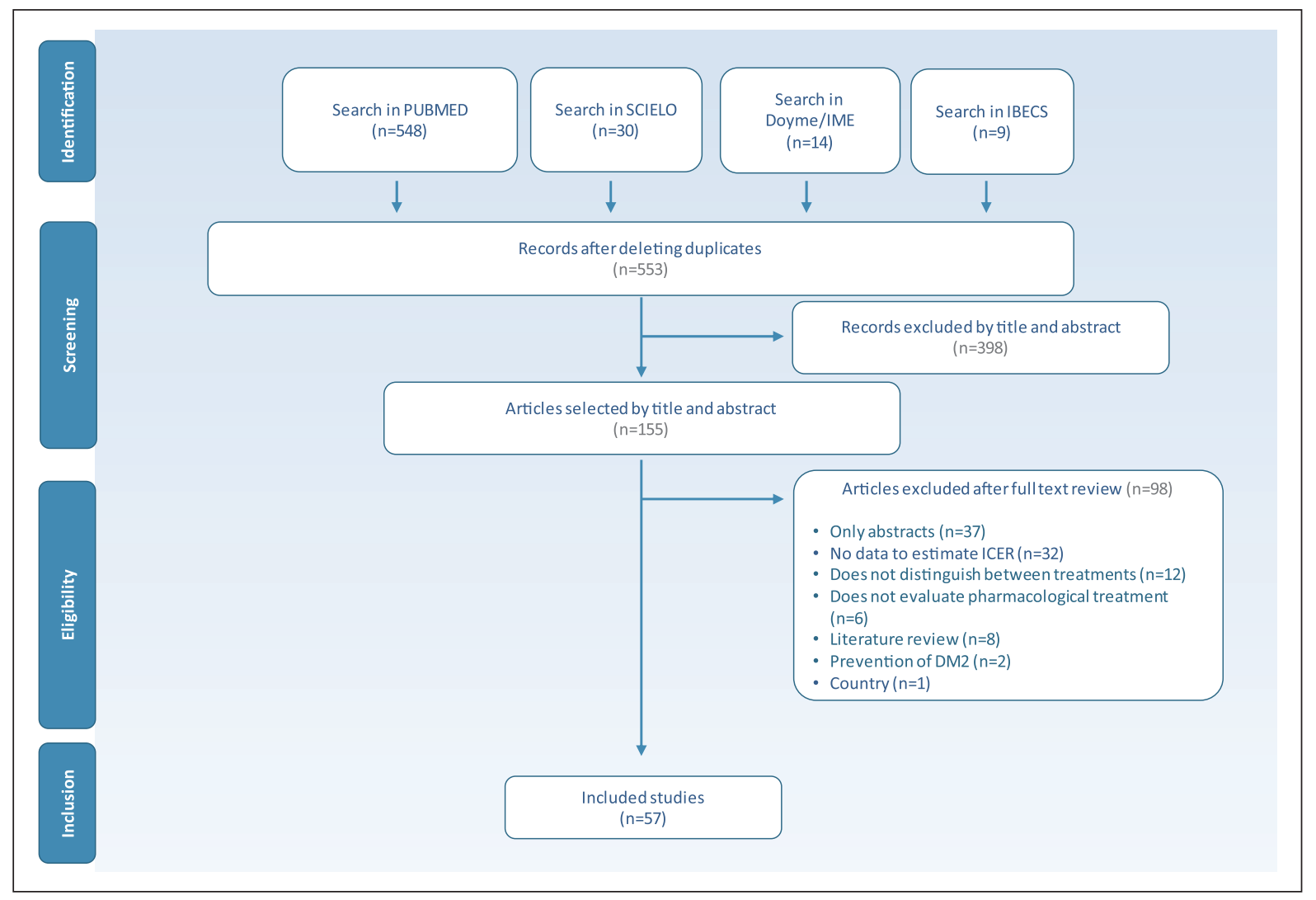

Figure I. Flow diagram of PRISMA about the process of bibliographic search and selection of studies.

The comparisons can be considered from the perspective of the treatment or of the comparator. Thus, there will be 134 comparisons in one way and another 134 comparisons in the opposite way. The comparisons can relate to two of the types of NIADs included or to one of them compared to another antidiabetic drug, not a subject of this review, such as acarbose, insulin or placebo. Since only those comparisons of two NIADs that were subject to this study's review were considered twice, we finally analysed a total of 223 comparisons (Figure 2).

In these 134 comparisons, 22 NIADs (or NIAD groups) that were the subject of this review participated. No study included gliclazide, linagliptin or empagliflozin. The aGLP-1 liraglutide was the most frequently evaluated active substance (48 times), followed by the aGLP-1 exenatide (38 times) and the iDPP4 sitagliptin (21 times). Insulin, sitagliptin and glipizide were the most commonly used drugs as comparators (37, 16 and 13 times, respectively) (Figure 2). The most frequent comparison was exenatide versus insulin (18 times), followed by liraglutide versus sitagliptin and liraglutide versus exenatide (nine times each) (Figure 3 ).

With regard to the main characteristics of the 57 studies included in the review, the following aspects should be noted (Table 3). $77 \%$ of the studies were carried out in European countries, although the United States was the
Table 2. Number of comparisons extracted from each of the 57 studies included.

\begin{tabular}{llc}
\hline $\begin{array}{l}\text { Comparisons } \\
\text { per study }(\mathrm{a})\end{array}$ & $\begin{array}{l}\text { Number of } \\
\text { studies }(\mathrm{b})\end{array}$ & $\begin{array}{l}\text { Total number of } \\
\text { comparisons }(\mathrm{a} \times \mathrm{b})\end{array}$ \\
\hline I comparison & 28 & 28 \\
2 comparisons & 14 & 28 \\
3 comparisons & 5 & 15 \\
4 comparisons & 3 & 12 \\
5 comparisons & 1 & 5 \\
6 comparisons & 3 & 18 \\
10 comparisons & 1 & 10 \\
18 comparisons & 1 & 18 \\
& 57 & 134 \\
\hline
\end{tabular}

predominant country of reference, with 10 studies. The perspective of the analysis most frequently used was that of the healthcare financer (in 53 studies), while four of them considered the social perspective, that is, they included both direct and indirect costs. ${ }^{20-23}$ In $88 \%$ of cases, baseline data about patients and treatment efficacy came from randomised clinical trials: 35 studies used data from a unique clinical trial (17 different trials), 4 studies were anchored on various trials $(n=4)$ and 11 studies used information arising from a literature review or metaanalysis $(n=11)$. The remaining $12 \%$ of cases came from 


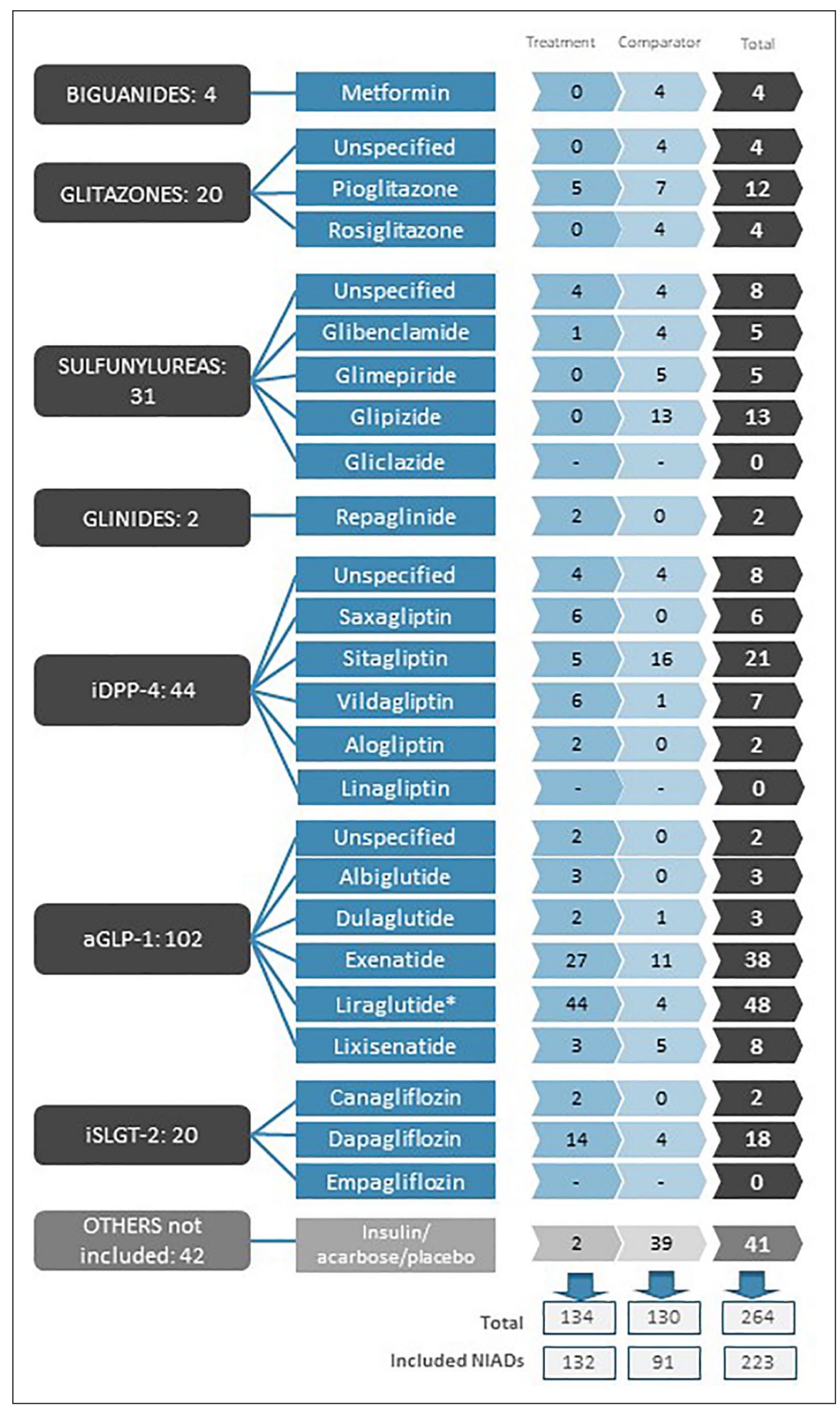

Figure 2. Drugs participating in the 134 comparisons drawn from the 57 studies. *Co-formulation liraglutide-insulin degludec. 


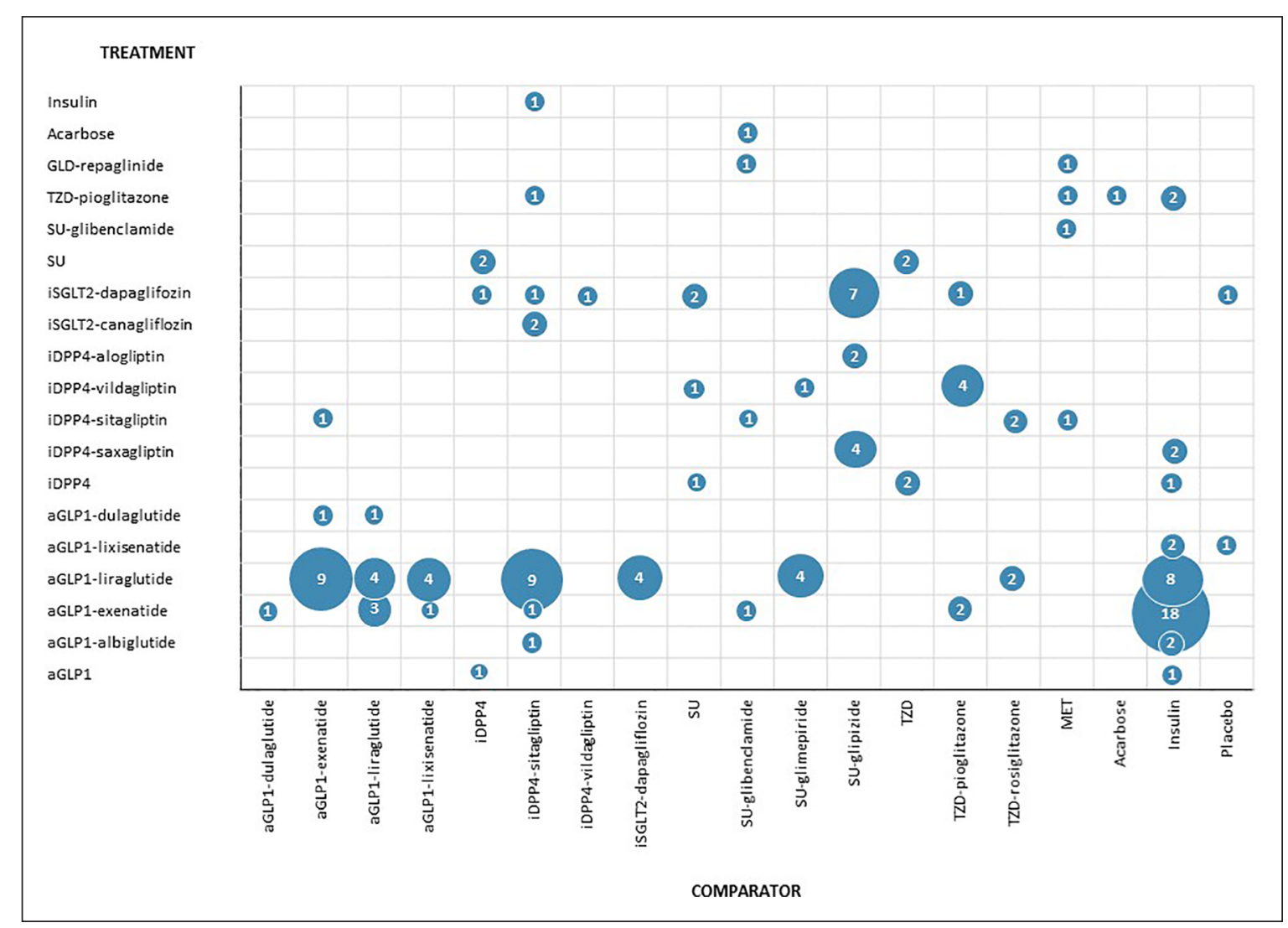

Figure 3. Diagram of the comparisons extracted from the 57 studies included depending on whether the drug acts as a treatment or as a comparator.

Source: Own preparation.

observational studies $(n=4)$ or from patients' databases $(\mathrm{n}=3)$.

The most frequently used time horizon was 40 years $(n=21)$, followed by between $45-50$ years $(n=11)$ and 35 years $(n=8)$. The most used simulation models were the CORE Diabetes Model $(n=25)$ and the Cardiff Diabetes Model $(n=16) .52$ of the 57 studies discounted the results, and only two of them applied a discount rate to the costs that were different from that applied to the clinical benefits. $^{24,25}$ The most common discount rate was 3\% $(n=23)$, followed by $3.5 \%(n=18) .91 \%$ of the studies performed a sensitivity analysis on the results $(n=52)$. In 11 studies, the analysis was only deterministic, and in the other 41 studies, it was both deterministic and probabilistic.

Regarding the characteristics of the clinical trials used as a source of efficacy data, and the baseline characteristics of the patients included, the following points should be noted (Table 4). The duration of the trials ranged between 18 weeks and 2 years, the most common duration among the comparisons was 26 weeks (6 months) $(n=40)$. The sample size of the clinical trials varied considerably. The average age of the subjects included in the trials was 57.2 years, and most of the comparisons $(n=94)$ were based on trials whose subjects had an average age between
55 and 60 years. The average duration of diabetes type II was 6-7years $(n=52)$. Diabetes was newly diagnosed only in three of the combinations extracted, while in 17 combinations the patients had had the disease for more than 10 years. $9 \%$ of the studies were based on trials conducted on a sample of overweight patients, while in $77 \%$ of the comparisons made, the sample of patients had an average body mass index (BMI) of more than 30 (obesity). Sadly, the high heterogeneity of the studies, as well as the limitations in the information offered, prevented us from offering a quantitative synthesis of the studies or a global summary measure.

\section{Quality of the studies}

The quality of the economic evaluations found, which was evaluated using the Drummond checklist, ${ }^{19}$ was acceptable (Figure 4). The aspects most appropriately collected in the studies were the research question (P1.), the answer to the question of the study (P33.) and the derivation of conclusions (P34.), while the most common problems found, were those related to the details of the statistical tests and confidence intervals (P26.), the justification of the choice of the discount rate (P24.), the questions of 
Table 3. General characteristics of the 57 studies included in the review.

\begin{tabular}{|c|c|c|c|c|c|}
\hline Year of publication & $N(n=57)$ & $\%$ & Country & $N(n=57)$ & $\%$ \\
\hline 2010 & 4 & 7.0 & Spain & 7 & 12.3 \\
\hline 2011 & 6 & 10.5 & Other European countries & 37 & 64.9 \\
\hline 2012 & 8 & 14.0 & USA & 10 & 17.5 \\
\hline 2013 & 2 & 3.5 & Canada & 3 & 5.3 \\
\hline 2014 & 6 & 10.5 & \multicolumn{3}{|l|}{ Perspective of the study } \\
\hline 2015 & 8 & 14.0 & Healthcare financing & 53 & 93.0 \\
\hline 2016 & 9 & 15.8 & Social & 4 & 7.0 \\
\hline 2017 & 14 & 24.6 & \multicolumn{3}{|l|}{ Type of costs included } \\
\hline \multicolumn{3}{|l|}{ Year reference of costs } & Pharmacological only & 1 & 1.8 \\
\hline 2007-2009 & 13 & 22.8 & Drugs + treatment of complications & 47 & 82.5 \\
\hline $2010-2012$ & 16 & 28.1 & All direct healthcare & 2 & 3.5 \\
\hline $2013-2014$ & 13 & 22.8 & Direct and indirect & 4 & 7.0 \\
\hline $2015-2016$ & 14 & 24.6 & NA & 3 & 5.3 \\
\hline NA & I & 1.8 & & & \\
\hline Source of efficacy data & $N(n=57)$ & $\%$ & Time horizon & $N(n=57)$ & $\%$ \\
\hline Clinical trials & 39 & 68.4 & 5 years & I & 1.8 \\
\hline Observational & 4 & 7.0 & $10-20$ years & 4 & 7.0 \\
\hline Database & 3 & 5.3 & 35 years & 8 & 14.0 \\
\hline Review/meta-analysis & $\mathrm{II}$ & 19.3 & 40 years & 21 & 36.8 \\
\hline \multicolumn{3}{|l|}{ Cost discount rate (\%) } & $45-50$ years & 12 & 21.1 \\
\hline 5 & 6 & 10.5 & Lifetime & 10 & 17.5 \\
\hline 4 & 5 & 8.8 & NA & 1 & 1.8 \\
\hline 3.5 & 18 & 31.6 & \multicolumn{3}{|l|}{ Analysis of sensitivity } \\
\hline 3 & 23 & 40.4 & Deterministic only & II & 19.3 \\
\hline \multirow[t]{2}{*}{ NA } & 5 & 8.8 & Deterministic and probabilistic & 41 & 71.9 \\
\hline & & & None & 5 & 8.8 \\
\hline
\end{tabular}

NA: not available.

generalisation (P36.) and the justification of the model used and its key parameters (P21.).

\section{Efficiency of non-insulin antidiabetic treatments}

Table 5 summarises the efficiency results obtained for each comparison included in this review, considering a cost-effectiveness threshold of 25,000 euros per additional QALY gained. The detailed information contained in each study can be found in Table 6 .

Based on the results found, the inhibitors of SGLT-2 (dapagliflozin and canagliflozin) were preferable, in terms of cost-effectiveness, to the iDPP-4, the sulphonylureas and pioglitazone. ${ }^{22,26-34}$ However, the same cannot be said about their superiority over the aGLP-1 (Table 5, Figure 5). Specifically, the iSGLT-2 participated in 20 of 223 comparisons included (18 for dapagliflozin and 2 for canagliflozin), which were extracted from 10 economic evaluations. No comparison was found between these two
iSGLT-2, nor any for empagliflozin. Dapagliflozin was a more efficient option than the iDPP-4: it was dominant (less expensive and more effective) versus the group of iDPP-4 in general; ${ }^{26}$ and cost-effective versus sitagliptin ${ }^{27}$ and vildagliptin, ${ }^{28}$ with incremental cost-effectiveness ratios (ICERs) of $€ 8000$ and $€ 17,700$ updated to 2017 per QALY gained, respectively. Dapagliflozin was also cost-effective versus the sulphonylureas, both at the group level ${ }^{28,29}$ and versus glipizide $26,30-32$ and versus pioglitazone (TZD) (ICER of $€ 2.000 / \mathrm{QALY}){ }^{26}$ However, in the four comparisons with liraglutide, dapagliflozin was a dominant or non-costeffective option..$^{33}$ In addition, in the only two comparisons found for canagliflozin, from the same study in which different doses of this NIAD were evaluated versus sitagliptin in the third line of treatment, canagliflozin was a dominant treatment option when compared with this iDPP- $4 .{ }^{34}$

The results were not conclusive for the a GLP-1. ${ }^{20,21,23,25,33,35-66}$ Albiglutide appeared to be a more cost-effective option than sitagliptin, ${ }^{35}$ but the results were the opposite when 
Table 4. Duration and sample size of clinical trials.

\begin{tabular}{|c|c|c|c|c|c|}
\hline Duration of the trial & $N(n=134)$ & $\%$ & Sample size & $N(n=134)$ & $\%$ \\
\hline$<20$ weeks & 2 & 1.5 & $<400$ & II & 8.2 \\
\hline 20-30 weeks & 48 & 35.8 & $400-500$ & 36 & 26.9 \\
\hline $31-52$ weeks & 25 & 18.7 & $500-800$ & 9 & 6.7 \\
\hline$>52$ weeks & 5 & 3.7 & $800-1000$ & II & 8.2 \\
\hline \multirow[t]{3}{*}{ NA } & 54 & 40.3 & $1000-2000$ & 5 & 3.7 \\
\hline & & & $>2000$ & 7 & 5.2 \\
\hline & & & NA & 55 & 41.0 \\
\hline
\end{tabular}

Baseline characteristics of the patients

\begin{tabular}{|c|c|c|c|c|c|}
\hline Sex & $N(n=134)$ & $\%$ & Age & $N(n=134)$ & $\%$ \\
\hline $30 \%-40 \%$ women & 13 & 9.7 & 50-55 years & 16 & 11.9 \\
\hline $40 \%-45 \%$ women & 31 & 23.1 & $55-60$ years & 94 & 70.1 \\
\hline $45 \%-50 \%$ women & 54 & 40.3 & $>59$ years & 9 & 6.7 \\
\hline $50 \%-60 \%$ women & 14 & 10.4 & NA & 15 & 11.2 \\
\hline NA & 22 & 16.4 & & & \\
\hline \multicolumn{3}{|l|}{ Duration of DM2 } & \multicolumn{3}{|c|}{ Patients' BMI } \\
\hline$<$ I year & 3 & 2.2 & $<30$ & 12 & 9.0 \\
\hline $1-5$ years & 5 & 3.7 & $30-34$ & 96 & 71.6 \\
\hline $5-6$ years & 10 & 7.5 & $>34$ & 7 & 5.2 \\
\hline $6-7$ years & 52 & 38.8 & NA & 19 & 14.2 \\
\hline 7-8years & 3 & 2.2 & \multicolumn{3}{|c|}{ Level of $\mathrm{HbAIC}$} \\
\hline 8-9years & 16 & 11.9 & $<7 \%$ & 3 & 2.2 \\
\hline $9-10$ years & 20 & 14.9 & $7-8 \%$ & 33 & 24.6 \\
\hline$>10$ years & 17 & 12.7 & $>8 \%$ & 95 & 70.9 \\
\hline NA & 8 & 6.0 & NA & 3 & 2.2 \\
\hline
\end{tabular}

BMI: body mass index; DM2: diabetes mellitus type 2; NA: not available or not applicable.

comparing the general subgroups to which these NIADs belonged (aGLP-1 versus iDPP-4). ${ }^{20}$ Exenatide was a more cost-effective treatment than another analogue such as lixisenatide (ICER of $€ 12,600 / \mathrm{QALY}),{ }^{36}$ but no conclusive results were obtained in comparison with other analogues such as liraglutide, ${ }^{36-41}$ or dulaglutide. ${ }^{36,42}$ Nor were the results conclusive for sitagliptin, where converse results were obtained. ${ }^{43,44}$ Exenatide was a dominant option over pioglitazone in the two studies that analysed this comparison, ${ }^{43,45}$ but it was not cost-effective compared with a sulphonylurea such as glibenclamide. ${ }^{44}$ In terms of cost-effectiveness, the results for liraglutide were favourable versus dapagliflozin, ${ }^{33}$ but the results compared with other aGLP-1 were inconclusive: it was a dominated option versus dulaglutide ${ }^{46}$ and cost-effective or dominant versus lixisenatide, ${ }^{47-49,67}$ but with divergent results versus exenatide. ${ }^{36-41}$ Liraglutide was cost-effective versus sitagliptin (iDPP-4) in 8 of the 9 comparisons found, ${ }^{21,37,50-54}$ and was a cost-effective option versus glimepiride in 3 of the 4 comparisons, ${ }^{21,50,53}$ but not versus rosiglitazone. ${ }^{55}$ Lixisenatide did not appear to be a more cost-effective option than other analogues such as exenatide ${ }^{36}$ or liraglutide. ${ }^{39,47-49}$ Dulaglutide was dominant over liraglutide, ${ }^{46}$ but contradictory results were obtained versus exenatide. ${ }^{36,42}$

For the iDPP-4, no conclusive results were obtained, ${ }^{20,21,24,26-28,34,35,37,43,44,50-54,56,68-77}$ except when they were compared with the iSGLT-2. In this case, their results were favourable in all comparisons made at group and individual level. ${ }^{26,28,30,34}$ At the group level, the iDPP-4 were more cost-effective than the aGLP1 ${ }^{20}$ and glitazones. ${ }^{69,70}$ However, a specific iDPP-4 such as sitagliptin was a noncost-effective option compared with an aGLP1 such as albiglutide $^{35}$ and there were contradictory results for the glitazones, which dominated rosiglitazone, ${ }^{56}$ but were dominated by pioglitazone. ${ }^{35,71}$ When these NIADs were compared with the sulphonylureas, there were again no clear results: at the group level, the results were inconclusive; ${ }^{69,70}$ saxagliptin and alogliptin were more cost-effective than glipizide, ${ }^{68,78}$ and vildagliptin was cost-effective versus glimepiride ${ }^{72}$ and versus sulphonylureas in general; ${ }^{73}$ but sitagliptin did not appear to be cost-effective compared with a sulphonylurea such as glibenclamide used in the 


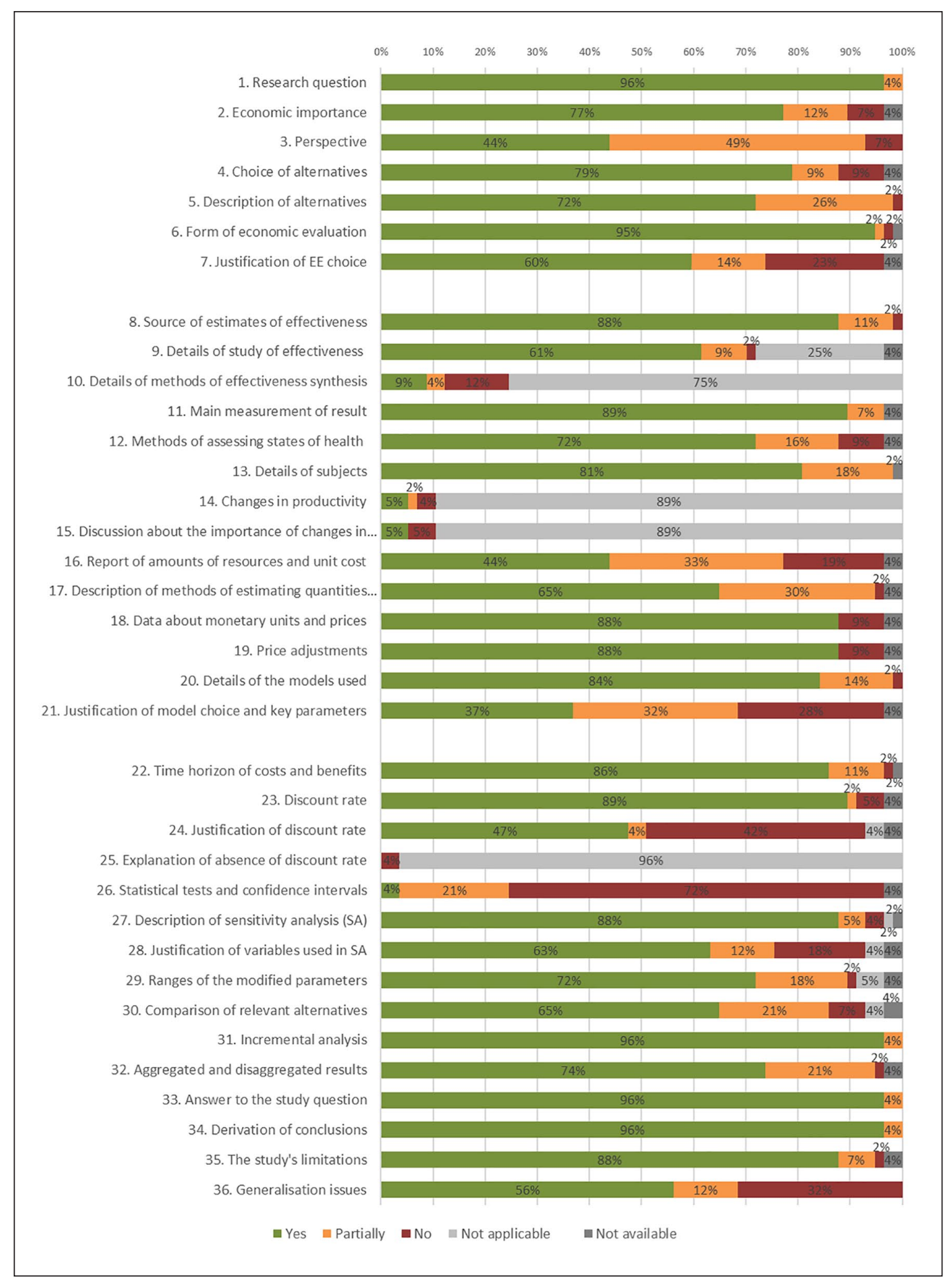

Figure 4. Results of the evaluation of the methodological quality applied in the studies included in the review. Source: Own preparation based on Drummond's checklist. ${ }^{19}$

second line. ${ }^{44}$ The only iDPP-4 which was compared with an aGLP-1 was sitagliptin, but no conclusive results in only one way were obtained: it was not cost-effective versus albiglutide ${ }^{35}$ and there were converse results versus exenatide ${ }^{43,44}$ and liraglutide. ${ }^{21,37,50-54}$

Nor were the results conclusive for the glitazones. ${ }^{26,43,45,55,56,69-71}$ At the group level, glitazones were a non-cost-effective option compared with the group of iDPP-4, ${ }^{69,70}$ and rosiglitazone was an option dominated by sitagliptin, ${ }^{56}$ but pioglitazone was dominant over sitagliptin, ${ }^{71}$ and there were conflicting results in the comparison with vildagliptin. ${ }^{56}$ Results were not conclusive in the comparison with the sulphonylureas group, results being obtained in both ways. ${ }^{69,70}$ When compared with the aGLP-1, pioglitazone had 
Table 5. Summary of the results of the economic evaluations included in terms of incremental cost per QALY gained for the NIADs (threshold $€ 25,000 / Q A L Y$ ).

\begin{tabular}{|c|c|}
\hline Comparisons (number) & Results \\
\hline \multicolumn{2}{|l|}{ Comparisons for inhibitors of SGLT-2 } \\
\hline Canagliflozin versus sitagliptin $(n=2)$ & Dominant \\
\hline Dapagliflozin versus liraglutide $(n=4)$ & Dominated in 2; not cost-effective in 2 \\
\hline Dapagliflozin versus iDPP-4 $(n=I)$ & Dominant \\
\hline Dapagliflozin versus sitagliptin $(n=1)$ & Cost-effective \\
\hline Dapagliflozin versus vildagliptin $(n=I)$ & Cost-effective \\
\hline Dapagliflozin versus pioglitazone $(n=I)$ & Cost-effective \\
\hline Dapagliflozin versus sulphonylurea $(n=2)$ & Cost-effective \\
\hline Dapagliflozin versus glipizide $(n=7)$ & Cost-effective \\
\hline Dapagliflozin versus placebo $(n=I)$ & Cost-effective \\
\hline \multicolumn{2}{|l|}{ Comparisons for analogues of GLP-I } \\
\hline aGLP-I versus iDPP-4 $(n=I)$ & Not cost-effective \\
\hline aGLP-I versus insulin $(n=I)$ & Cost-effective \\
\hline Albiglutide versus sitagliptin $(n=1)$ & Cost-effective \\
\hline Albiglutide versus insulin lispro $(n=1)$ & Not cost-effective \\
\hline Albiglutide versus insulin glargine $(n=I)$ & Not cost-effective \\
\hline Dulaglutide versus exenatide $(n=2)$ & Not cost-effective in I; dominant in I \\
\hline Dulaglutide versus liraglutide $(n=I)$ & Dominant \\
\hline Exenatide versus dulaglutide $(n=2)$ & Cost-effective in I; dominated in I \\
\hline Exenatide versus liraglutide $(n=12)$ & $\begin{array}{l}\text { Dominant in I; cost-effective in 3; not cost- } \\
\text { effective in } 7 \text {; dominated in I }\end{array}$ \\
\hline Exenatide versus lixisenatide $(n=I)$ & Cost-effective \\
\hline Exenatide versus sitagliptin $(n=2)$ & Dominant in I; dominated in I \\
\hline Exenatide versus pioglitazone $(n=2)$ & Dominant \\
\hline Exenatide versus glibenclamide $(n=I)$ & Not cost-effective \\
\hline Exenatide versus insulin glargine $(n=17)$ & $\begin{array}{l}\text { Dominant in 2; cost-effective in } 11 \text {; not cost- } \\
\text { effective in } 4\end{array}$ \\
\hline Exenatide versus insulin lispro $(n=I)$ & Cost-effective \\
\hline Liraglutide versus dapagliflozin $(n=4)$ & Dominant in 2; cost-effective in 2 \\
\hline Liraglutide versus dulaglutide $(n=I)$ & Dominated \\
\hline Liraglutide versus exenatide $(n=12)$ & $\begin{array}{l}\text { Cost-effective in 7; not cost-effective in } 3 \text {; } \\
\text { dominated in I; dominant in I }\end{array}$ \\
\hline Liraglutide versus lixisenatide $(n=4)$ & Cost-effective in 3 ; dominant in I \\
\hline Liraglutide versus sitagliptin $(n=9)$ & Cost-effective in 8; not cost-effective in I \\
\hline Liraglutide versus rosiglitazone $(n=2)$ & Not cost-effective \\
\hline Liraglutide versus glimepiride $(n=4)$ & Cost-effective in 3 ; not cost-effective in I \\
\hline Liraglutide-insulin (co-formulation) versus insulin $(n=8)$ & Cost-effective in 5; dominant in 3 \\
\hline Liraglutide-insulin (co-formulation) versus liraglutide + insulin $(n=4)$ & Co-formulation dominant in 3; cost-effective in I \\
\hline Lixisenatide versus exenatide $(n=I)$ & Not cost-effective \\
\hline Lixisenatide versus liraglutide $(n=4)$ & Not cost-effective in 3; dominated in I \\
\hline Lixisenatide versus insulin (bolos) $(n=2)$ & Dominant \\
\hline Lixisenatide versus placebo $(n=1)$ & Not cost-effective \\
\hline \multicolumn{2}{|l|}{ Comparisons for inhibitors of DPP-4 } \\
\hline iDPP-4 versus dapagliflozin $(\mathrm{n}=\mathrm{I})$ & Dominated \\
\hline iDPP-4 versus aGLP-I $(n=1)$ & Cost-effective \\
\hline iDPP-4 versus TZD $(n=2)$ & Cost-effective \\
\hline iDPP-4 versus sulphonylurea $(n=3)$ & $\begin{array}{l}\text { Dominant in I; cost-effective in I; not cost- } \\
\text { effective in I }\end{array}$ \\
\hline iDPP-4 versus insulin NPH $(n=1)$ & Cost-effective \\
\hline Saxagliptin versus glipizide $(n=4)$ & Cost-effective \\
\hline Saxagliptin versus insulin NPH $(n=2)$ & Cost-effective \\
\hline Sitagliptin versus canagliflozin $(n=2)$ & Dominated \\
\hline
\end{tabular}


Table 5. (Continued)

\begin{tabular}{|c|c|}
\hline Comparisons (number) & Results \\
\hline Sitagliptin versus dapagliflozin $(n=I)$ & Not cost-effective \\
\hline Sitagliptin versus albiglutide $(n=I)$ & Not cost-effective \\
\hline Sitagliptin versus exenatide $(n=2)$ & Dominated in I; dominant in I \\
\hline Sitagliptin versus liraglutide $(n=9)$ & Cost-effective in 1 ; not cost-effective in 8 \\
\hline Sitagliptin versus pioglitazone $(n=I)$ & Dominated \\
\hline Sitagliptin versus rosiglitazone $(n=2)$ & Dominant \\
\hline Sitagliptin versus glibenclamide $(n=I)$ & Not cost-effective \\
\hline Sitagliptin versus metformin $(n=I)$ & Not cost-effective \\
\hline Sitagliptin versus insulin glargine $(n=I)$ & Dominated \\
\hline Vildagliptin versus dapagliflozin $(n=1)$ & Not cost-effective \\
\hline Vildagliptin versus pioglitazone $(n=4)$ & Dominant in 2; not cost-effective in 2 \\
\hline Vildagliptin versus sulphonylurea $(n=I)$ & Cost-effective \\
\hline Vildagliptin versus glimepiride $(n=I)$ & Dominant \\
\hline Alogliptina versus glipizide $(n=2)$ & Cost-effective \\
\hline \multicolumn{2}{|l|}{ Comparisons for glitazones } \\
\hline TZD versus iDPP-4 $(n=2)$ & Not cost-effective \\
\hline TZD versus sulphonylurea $(n=2)$ & Cost-effective in I; not cost-effective in I \\
\hline Pioglitazone versus dapagliflozin $(n=I)$ & Not cost-effective \\
\hline Pioglitazone versus exenatide $(n=2)$ & Dominated \\
\hline Pioglitazone versus sitagliptin $(n=I)$ & Dominant \\
\hline Pioglitazone versus vildagliptin $(n=4)$ & Cost-effective in 2; dominated in 2 \\
\hline Pioglitazone versus metformin $(n=I)$ & Not cost-effective \\
\hline Pioglitazone versus insulin NPH $(n=2)$ & Dominant \\
\hline Pioglitazone versus acarbose $(n=I)$ & Not cost-effective \\
\hline Rosiglitazone versus liraglutide $(n=2)$ & Cost-effective \\
\hline Rosiglitazone versus sitagliptin $(n=2)$ & Dominated \\
\hline \multicolumn{2}{|l|}{ Comparisons for glinides } \\
\hline Repaglinide versus glibenclamide $(n=I)$ & Dominated \\
\hline Repaglinide versus metformin $(n=I)$ & Not cost-effective \\
\hline \multicolumn{2}{|l|}{ Comparisons for sulphonylureas } \\
\hline Sulphonylurea versus dapagliflozin $(n=2)$ & Not cost-effective \\
\hline Sulphonylurea versus iDPP-4 $(n=3)$ & $\begin{array}{l}\text { Not cost-effective in I; cost-effective in I; } \\
\text { dominated in I }\end{array}$ \\
\hline Sulphonylurea versus vildagliptin $(n=I)$ & Not cost-effective \\
\hline Sulphonylurea versus TZD $(n=2)$ & Cost-effective in I; not cost-effective in I \\
\hline Glibenclamide versus exenatide $(n=I)$ & Cost-effective \\
\hline Glibenclamide versus sitagliptin $(n=I)$ & Cost-effective \\
\hline Glibenclamide versus repaglinide $(n=I)$ & Dominant \\
\hline Glibenclamide versus metformin $(n=I)$ & Cost-effective \\
\hline Glibenclamide versus acarbose $(n=1)$ & Cost-effective \\
\hline Glimepiride versus liraglutide $(n=4)$ & Cost-effective in I; not cost-effective in 3 \\
\hline Glimepiride versus vildagliptin $(n=I)$ & Dominated \\
\hline Glipizide versus dapagliflozin $(n=7)$ & Not cost-effective \\
\hline Glipizide versus saxagliptin $(n=4)$ & Not cost-effective \\
\hline Glipizide versus alogliptina $(n=2)$ & Not cost-effective \\
\hline \multicolumn{2}{|l|}{ Comparisons for biguanides } \\
\hline Metformin versus sitagliptin $(n=I)$ & Cost-effective \\
\hline Metformin versus pioglitazone $(n=I)$ & Cost-effective \\
\hline Metformin versus repaglinide $(n=I)$ & Cost-effective \\
\hline Metformin versus glibenclamide $(n=I)$ & Not cost-effective \\
\hline
\end{tabular}

QALY: quality-adjusted life years; NIADs: non-insulin antidiabetic drugs; SGLT: sodium-glucose cotransporter type; DPP: dipeptidyl peptidase; GLP-I: glucagon-like peptide I; TZD: thiazolidinedione; NPH: neutral protamine Hagedorn. 


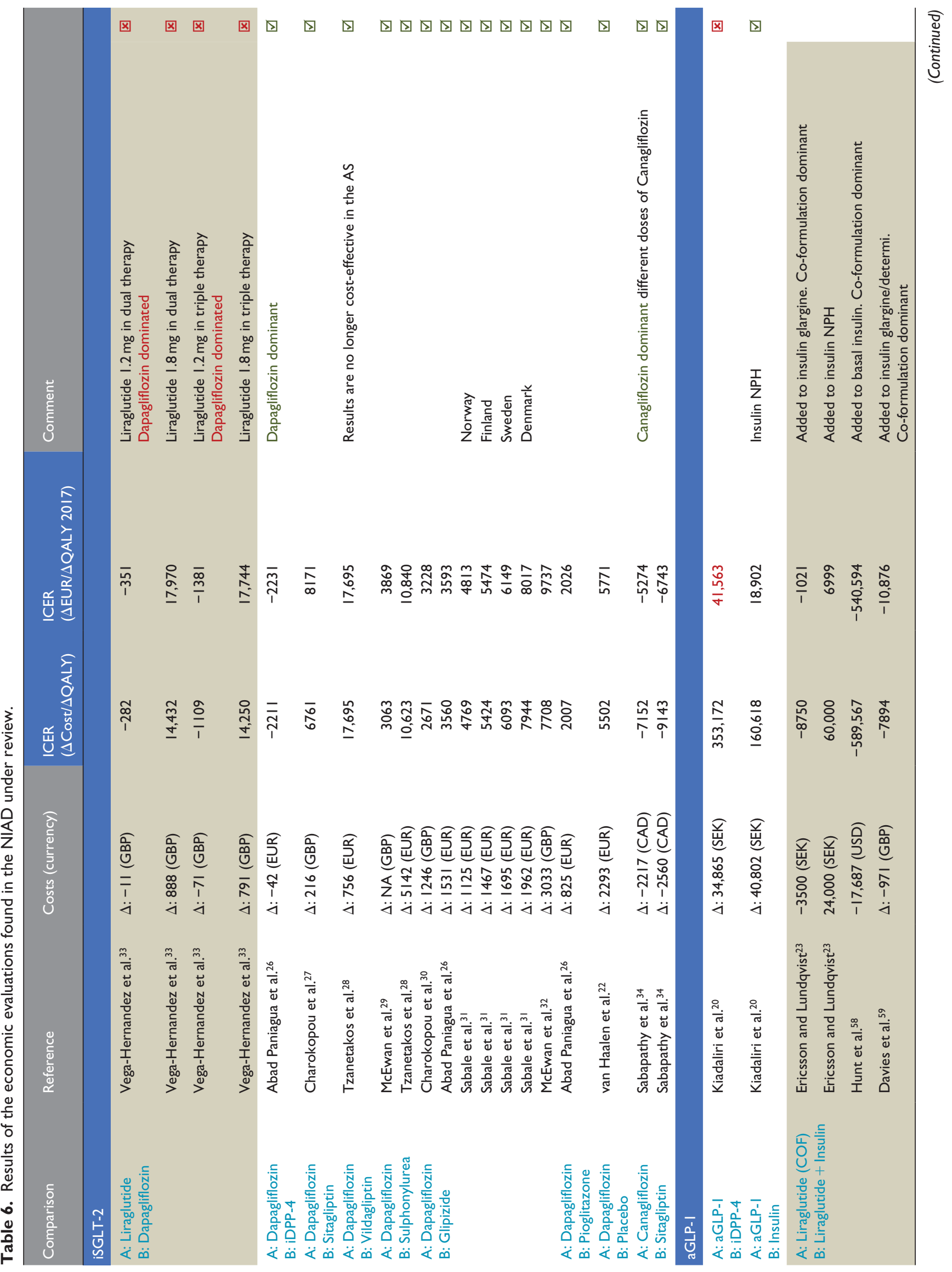




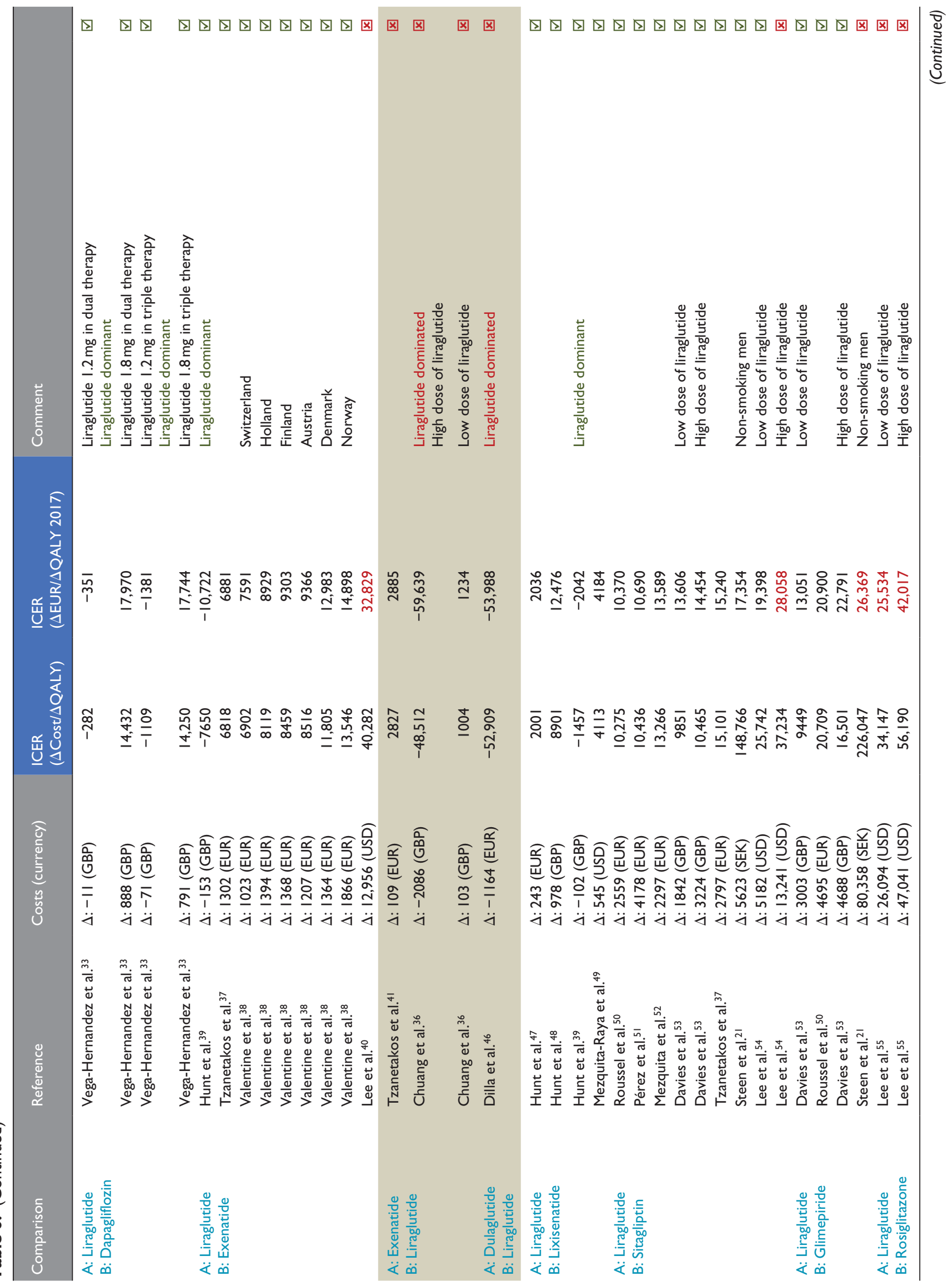




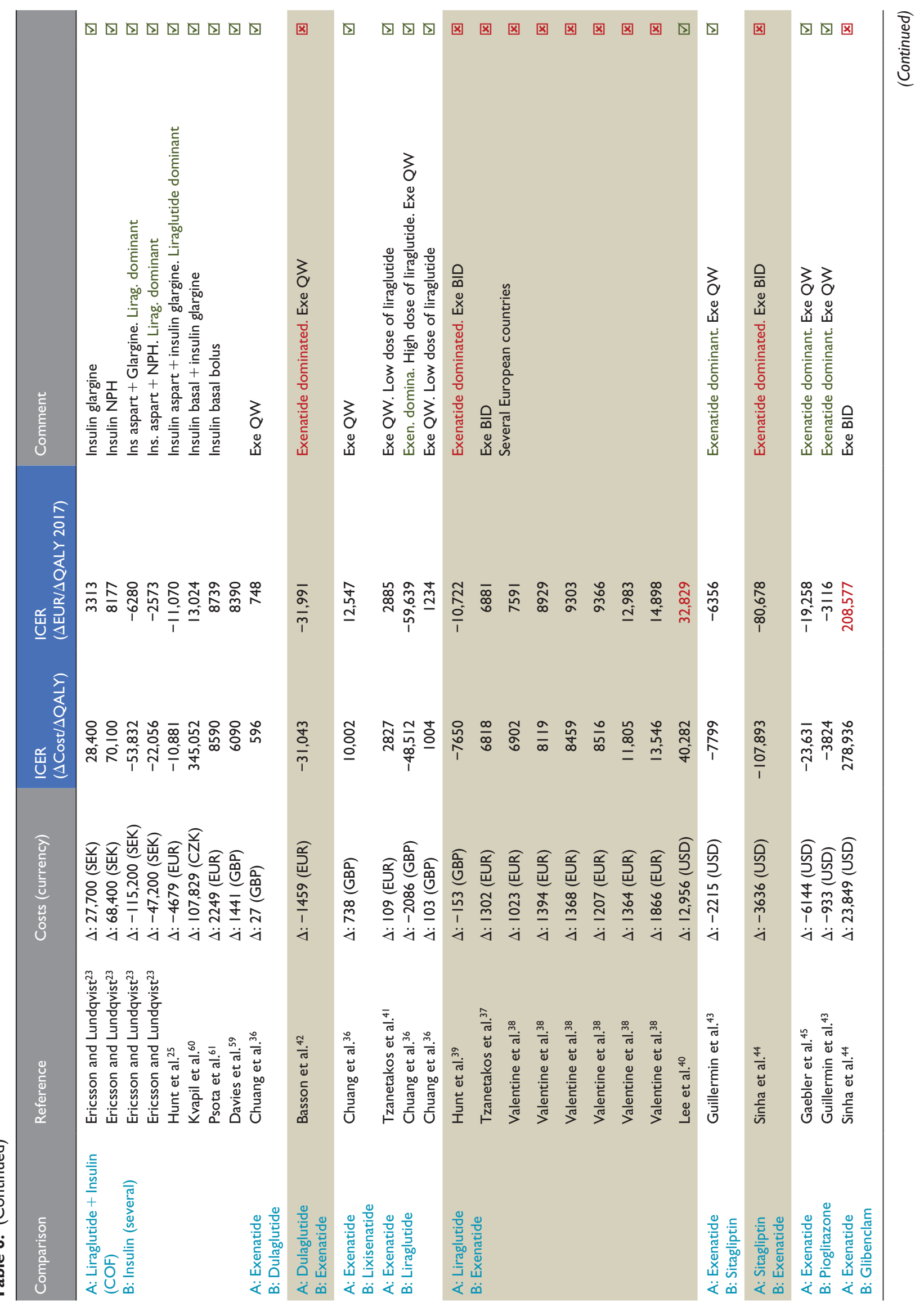




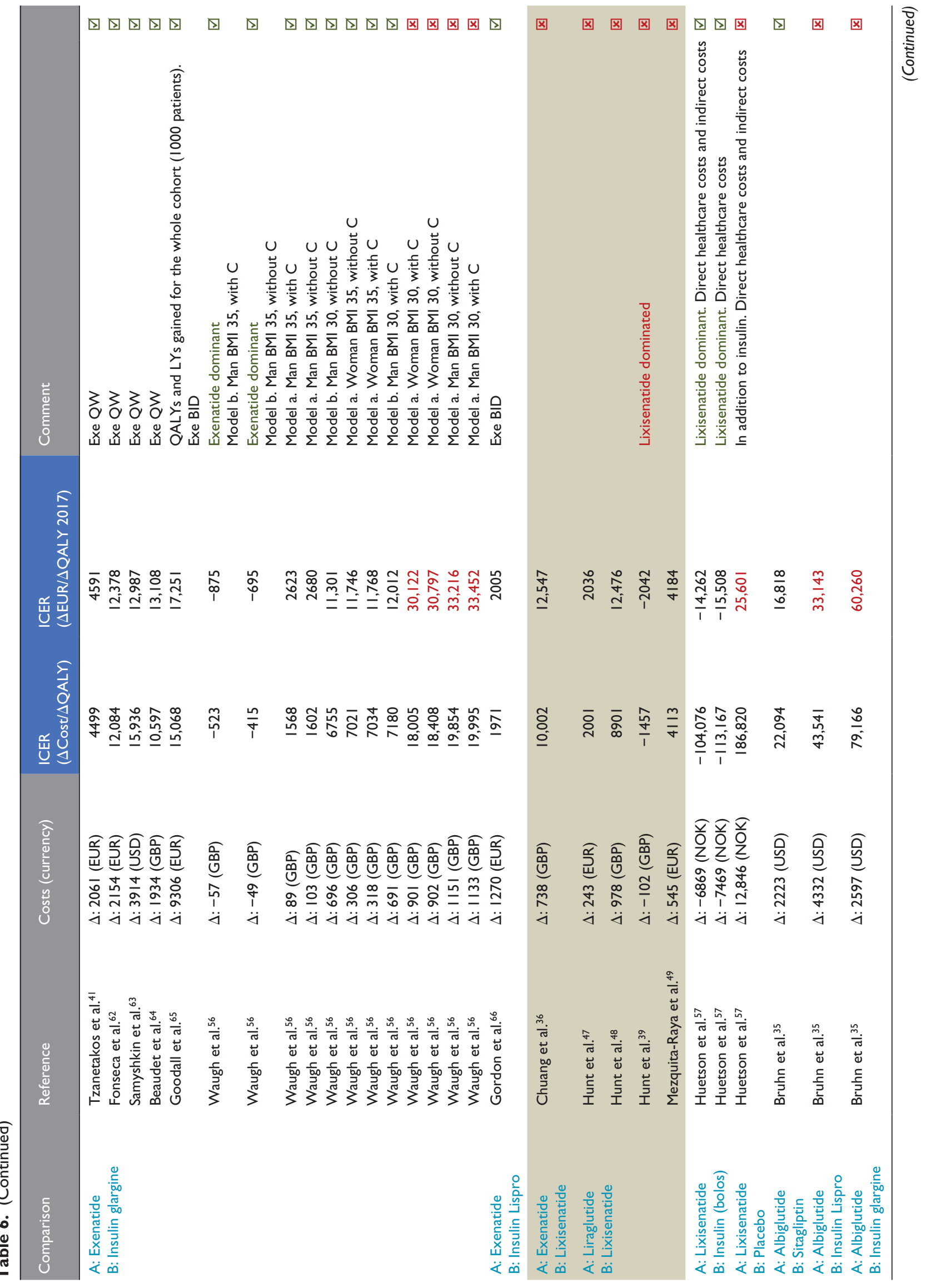




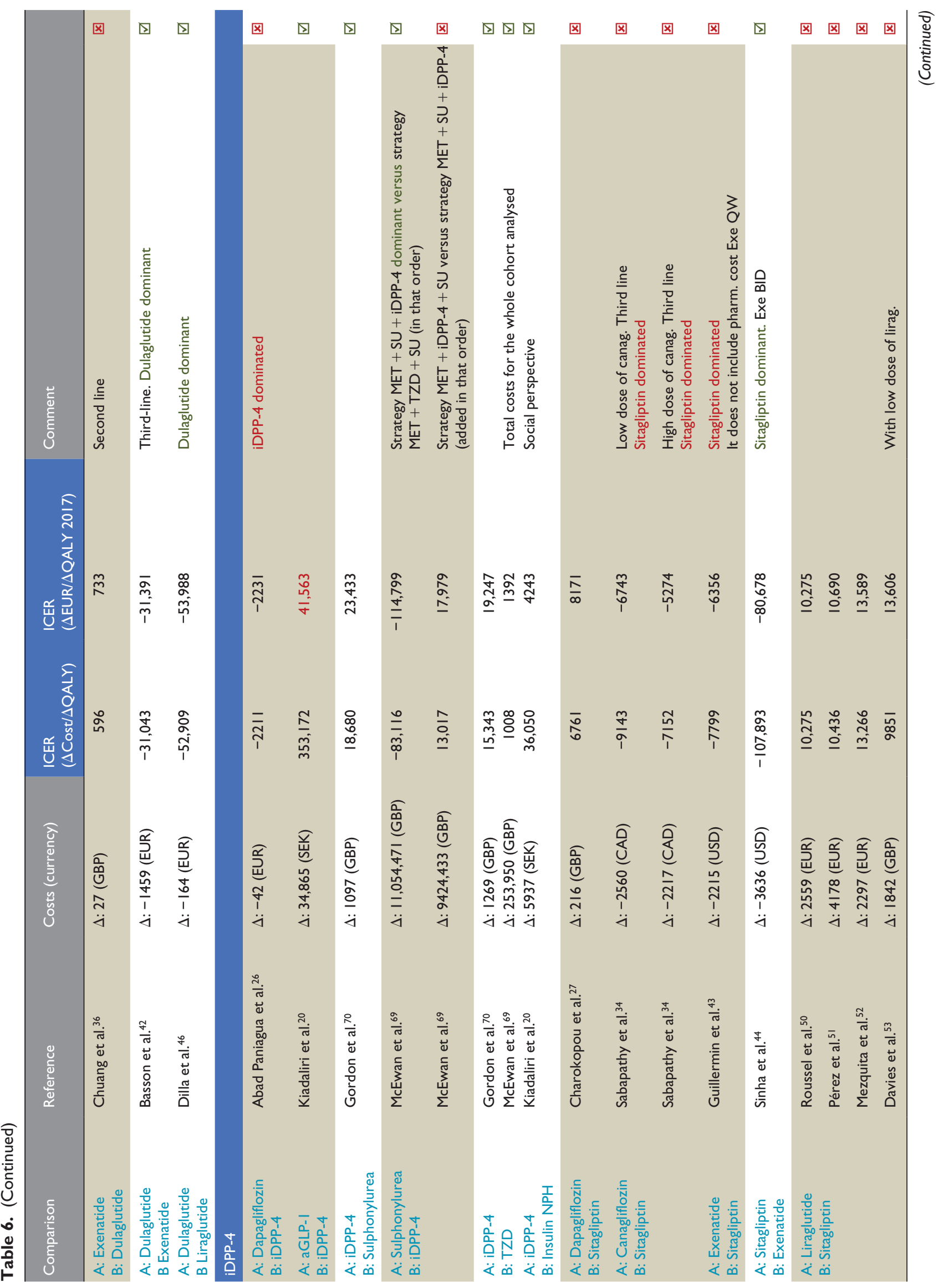




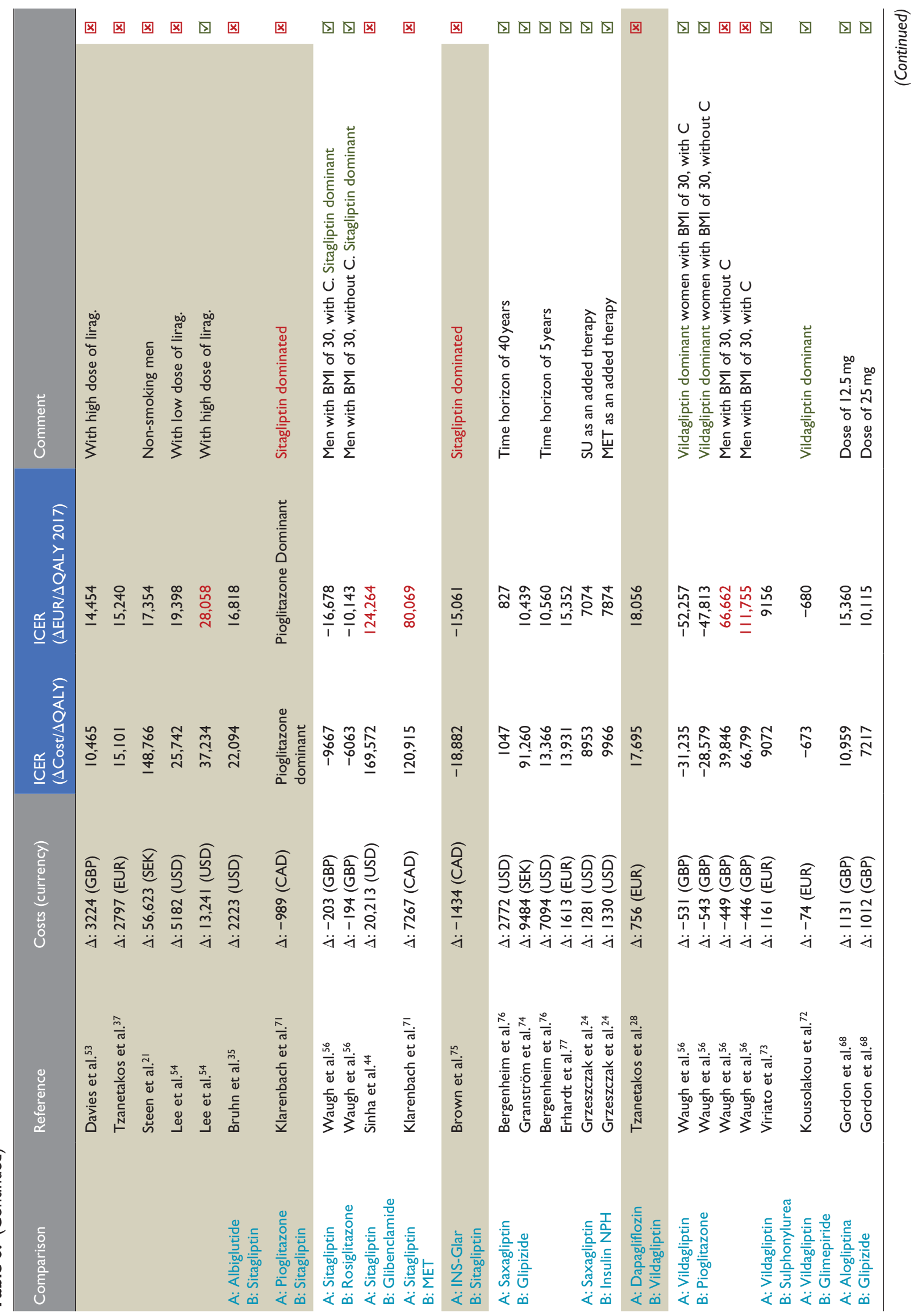




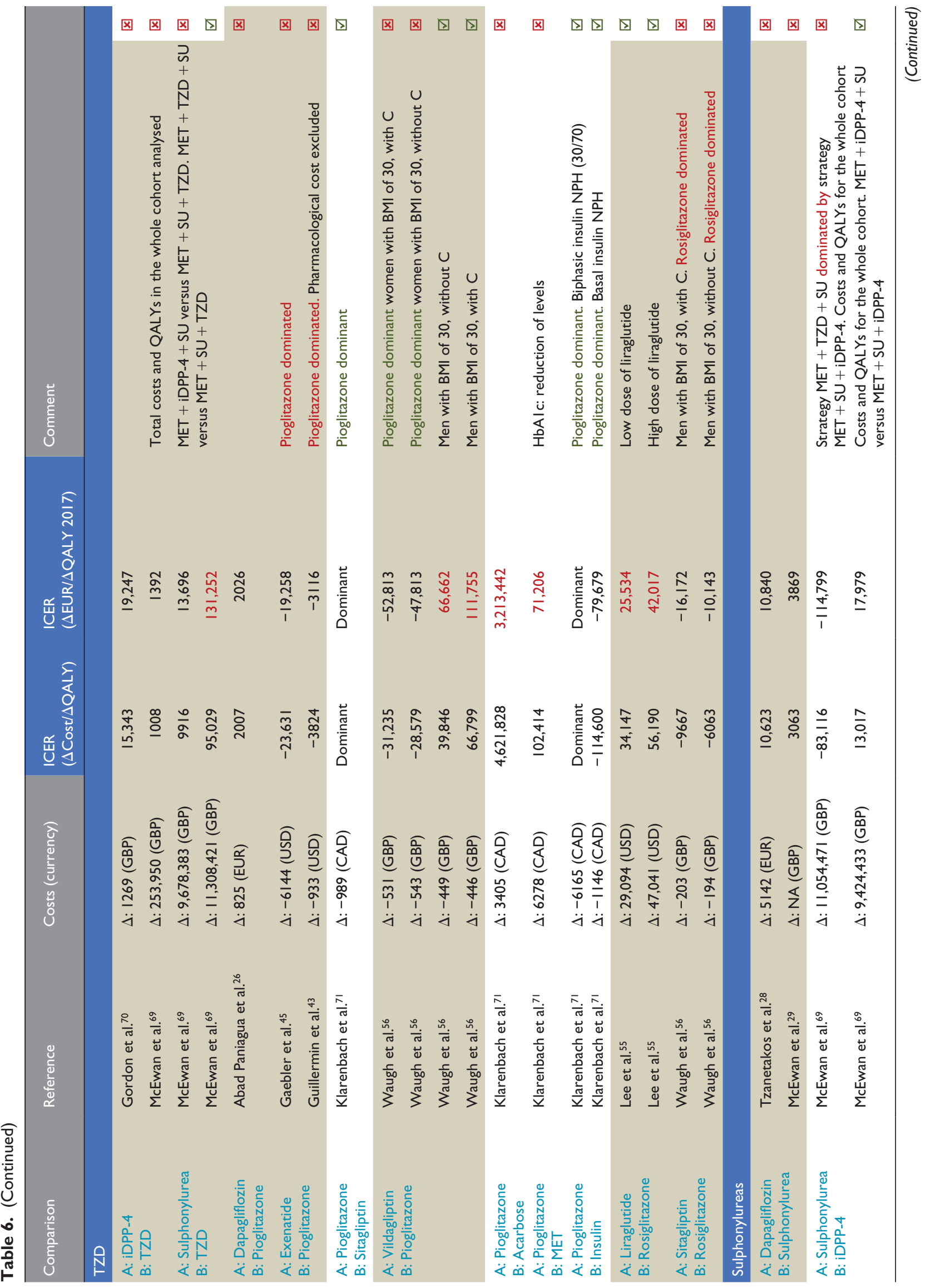




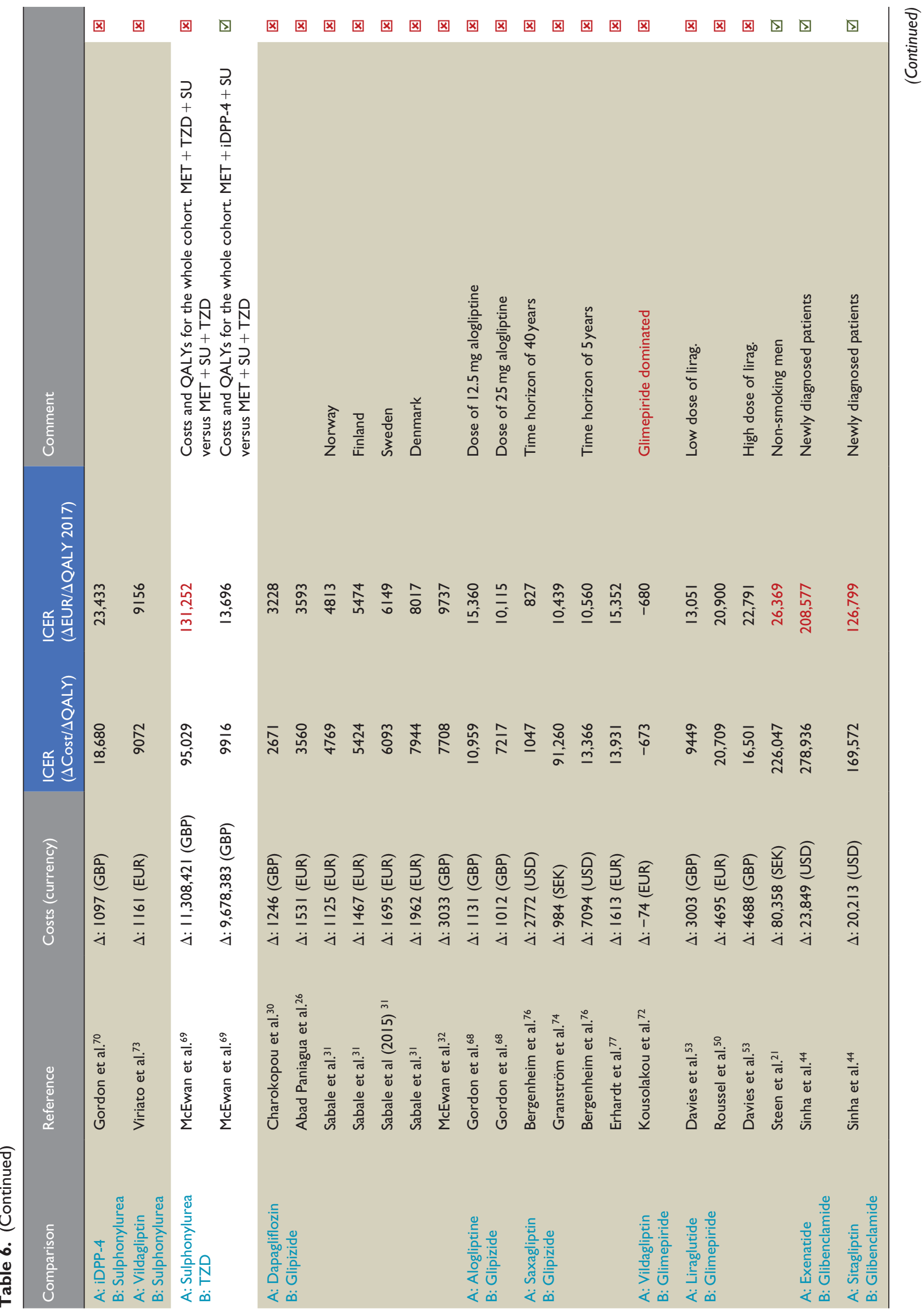




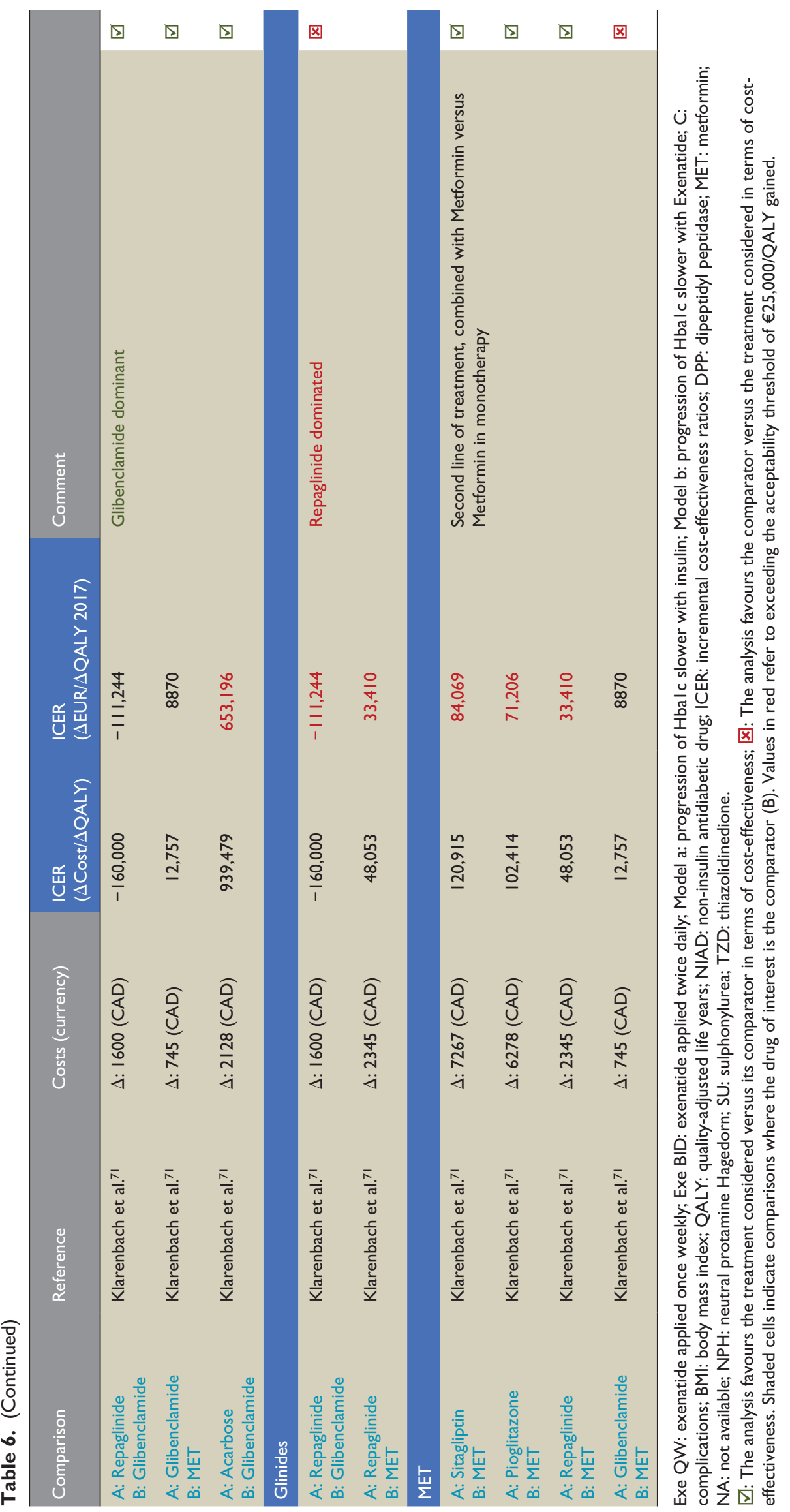




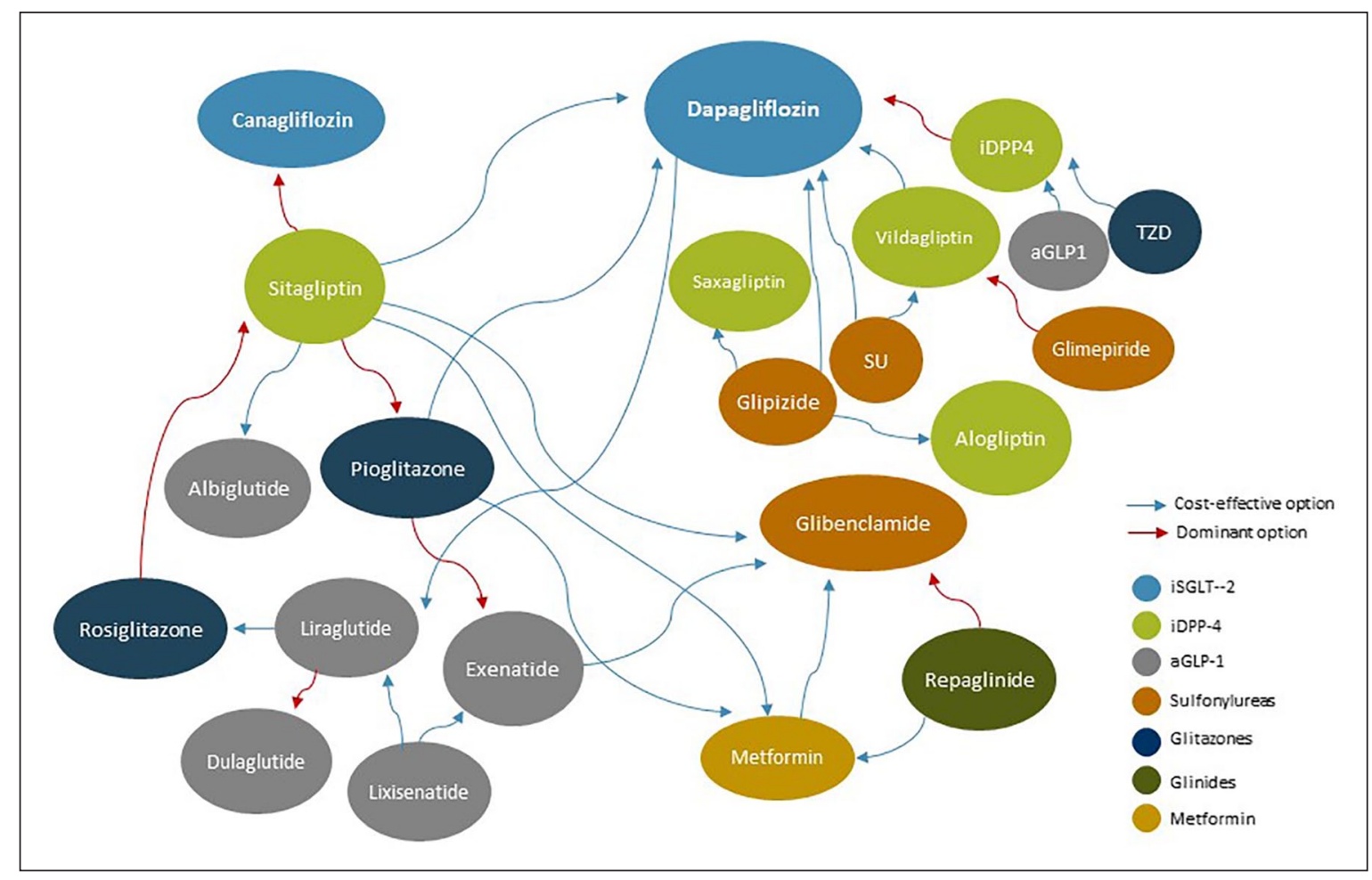

Figure 5. Summary of cost-effectiveness results found in the systematic review of literature 2010-2017, under the threshold of $€ 25,000 / Q A L Y$ gained, by NIAD groups.

The arrow points to the NIAD indicate that is cost-effective or dominant.

unfavourable results compared with exenatide, ${ }^{43,45}$ whereas rosiglitazone was a cost-effective option compared with liraglutide under the threshold considered. ${ }^{55}$ In the only comparison found with an iSGLT-2, dapagliflozin was more cost-effective than pioglitazone. ${ }^{26}$

Seen in the opposite way, it was not possible, either, to establish a clear option for sulphonylureas based on their efficiency, ${ }^{21,26,28-32,44,50,53,68-74,76,77}$ with the exception of dapagliflozin, which was more cost-effective than sulphonylureas in all the comparisons found. ${ }^{28,29}$ In contrast, the results were not conclusive either versus the group of iDPP-4 $4^{70,73}$ or versus the group of glitazones. ${ }^{69}$ Glibenclamide was a cost-effective option compared with sitagliptin, ${ }^{44}$ but glipizide was non-cost-effective compared with other iDPP-4 such as saxagliptin and alogliptin, ${ }^{68,74,78}$ and glimepiride was dominated by vildagliptina. ${ }^{72}$ Regarding the aGLP1, glibenclamide was cost-effective compared with exenatide, ${ }^{44}$ but there were no conclusive results for glimepiride versus liraglutide, ${ }^{21,50,53}$ regardless of the dose applied. Glibenclamide was a dominant option over repaglinide and more cost-effective than metformin. ${ }^{71}$

\section{Discussion}

Economic evaluation is a tool that facilitates complex decision-making. In the field of DM2, with the introduction of new therapeutic alternatives, often safer and more effective, but also more expensive than the previous ones, it has become more difficult to know which is the optimal pharmacological intensification. In this sense, this systematic review of the literature aims to help determine which NIADs are the most efficient in each case. To do so, we updated an earlier review, carried out in 2009, with the new evidence available, compiling the most recent economic evaluations and comparing the results obtained.

The description and analysis of the results were carried out by making comparisons among drugs, and not only among studies. To facilitate comparability, the incremental cost-utility ratios were updated to euros for 2017, and the implicit threshold of acceptability most recently published for Spain was used. ${ }^{18}$ The search of the literature yielded a total of 57 economic evaluations published in the last 8 years, from which it was possible to extract 134 comparisons for the included non-insulin antidiabetics. The results show the growing interest in economically evaluating the different NIADs. It seems that the debate about the first line of pharmacological treatment has already been overtaken, and the focus has shifted to an evaluation of the different NIADs among themselves in the second and third lines.

In this review, the only NIADs for which conclusive favourable results were obtained in terms of incremental cost-utility seem to be the iSGLT-2 versus the iDPP4, sulphonylureas and glitazones. In this regard, the literature 
has shown the usefulness of this type of NIADs among patients with long-term diabetes. ${ }^{26,34}$ In addition, the most recent NICE guidelines recommend, as the first treatment intensification, the addition of an iDPP-4, pioglitazone or a sulphonylurea to the metformin, opening the possibility of prescribing an iSGLT-2 in certain circumstances. ${ }^{79}$ In particular, the British agency states that iSGLT-2 can also be considered an alternative treatment in patients with inadequate glycaemic control, especially if they are overweight because they are associated with a loss of weight. Nevertheless, they should be prescribed with caution in patients with impaired renal function and propensity to suffer urinary tract infections. ${ }^{80-82}$ In triple therapy, the NICE places at the same level of recommendation as insulinisation, the adding of pioglitazone or an iDPP-4 to metformin-sulphonylurea, and keeps the aGLP-1 as a second option, while considering the use of iSGLT-2 as a third-line treatment option, either in combination with metformin, a sulphonylurea or a glitazone. ${ }^{81-83}$

When interpreting and contextualising the results of this review, certain considerations should be taken into account. First, the inclusion criteria are limited to studies published from 2010 onwards, so the conclusions apply specifically to those studies, which have been mainly performed with the most recently marketed drugs. This means that there is no general view of the cost-effectiveness of all available drugs; therefore, it is difficult to derive generic recommendations for use.

Second, the interpretation of the results obtained in terms of efficiency depends directly on the threshold of acceptability considered. Some countries have an explicit threshold, but this is not the case in Spain, so the maximum implicit threshold of acceptability published most recently for our country has been used: between $€ 21,000$ and $€ 24,000$ /QALY gained. ${ }^{18,84}$ Consequently, the conclusions obtained under this threshold will differ from the results of each study, which will take into account the threshold that applies to each area. Likewise, our conclusions could vary if the results obtained were considered under the prism of a substantially different alternative threshold.

Third, there is a high degree of heterogeneity in the methodology used in studies that evaluate the efficiency of these drugs, which makes it difficult to compare results and extrapolate conclusions. The studies use different sources of information, modelling of the disease, types of costs, discount rates, time horizons, baseline characteristics of patients, treatment intensification thresholds, sensitivity analyses and so on. The high degree of heterogeneity of the studies, together with the limitations in the information offered, prevented the formal estimation of an overall summary measurement through a meta-analysis.

Fourth, economic evaluations suffer from certain limitations. Data relating to effectiveness are often lacking, and efficacy data are only available from old clinical trials conducted in a given context and group of patients. ${ }^{85}$ Models, risk equations and assumed utilities were often developed for a different context and time, without necessarily being validated within the scope of the study. Likewise, there is uncertainty about the efficacy data and the costs of treatment in the medium/long term. ${ }^{67}$ The lack of information is alleviated by different assumptions, extrapolations and indirect evidence. ${ }^{27,57}$

Fifth, it is necessary to pay attention to the potential publication bias in the studies analysed. Publication bias appears because the studies published are usually those which are in favour of experimental treatment instead of control treatment. ${ }^{86,87}$ This and other biases (selection, implementation, detection, attrition and/or notification, ${ }^{88}$ quantifiable by different techniques, often come from the clinical trials on which efficacy and safety results are based, and which subsequently inherit the economic evaluations that are based on them. It should be mentioned that the good methodological practice of clinical trials and economic evaluations is the way to contain and manage the appearance of biases.

Finally, our study is not without limitations either. In systematic reviews, there is the possibility that the strategy has not been sufficiently sensitive when identifying relevant studies to answer the research question. However, a structured search approach has been followed so that the results are replicable. In addition, the cost-effectiveness ratios of the comparisons made, do not always appear in the studies but have sometimes been derived from the disaggregated results. In addition, the heterogeneity of the studies and the potential publication bias limit the external validity of the results, which in turn directly depend on the cost-effectiveness threshold considered. Finally, there are some NIADs for which no new evidence was found, as in the cases of gliclazide, empagliflozin, and linagliptin.

In conclusion, under an acceptability threshold of $€ 25,000 /$ QALY, the only NIADs for which conclusive favourable results seem to be obtained in terms of efficiency appear to be the ones most recently marketed, namely, the iSGLT-2 versus iDPP4, sulphonylureas and glitazones. However, these conclusions should be viewed with caution, since the heterogeneity between studies and results makes it difficult to draw unambiguous conclusions about the cost-effectiveness of the various NIADs, or to determine under what specific clinical conditions some non-insulin antidiabetics would be more effective than others. Also, the number of economic evaluations published about the iSGLT-2 is still short, and there is uncertainty about their safety and effectiveness in the medium and long term, so it does not seem appropriate to extrapolate the results to a generic recommendation of use. Some agencies warn about the increased risk of diabetic ketoacidosis, fractures, amputations and genitourinary infections ${ }^{79,89-91}$ associated with iSGLT-2.

This study aims to be one additional supportive tool in healthcare decision-making, but we must not lose 
sight of the fact that clinical criteria should always be the basis for deciding the most appropriated individualised treatment for each patient at each moment, based on their clinical characteristics and their preferences, in order to optimise the effectiveness of the treatment, but also the costs associated with the disease throughout the patient's life. ${ }^{5}$

In the future, it would be desirable to carry out more clinical trials and economic evaluations adapted to current clinical practice, as well as to limit to the highest extent the appearance of possible biases which may compromise the internal and external validity of the results.

\section{Acknowledgements}

The authors want to thank Jhon Galindo (Weber consultant) for the technical help performed with the figures and tables included in the article.

\section{Author contributions}

N.Z. developed the design and implementation of the review, the analysis of the results and the writing of the manuscript; A.S.G. provided a clinical review of the work. A.S.G., M.C. and S.S. helped to interpret the data and contributed to the final version of the manuscript. All authors approved the final version to be published.

\section{Availability of data and materials}

The datasets used during the current study are available from the corresponding author on a reasonable request.

\section{Ethical approval}

As a systematic review, this work did not require any Ethics Committee approval.

\section{Human rights}

This work did not involve human subjects.

\section{Informed consent}

As a systematic review, this work did not require any informed consent. No data of patients are shown.

\section{Declaration of conflicting interests}

M.C. and S.S. are employers of AstraZeneca. A.S.G. received funding for the clinical review of this article. N.Z. is employee of Weber, a consultancy firm which received research funding from AstraZeneca to conduct the study.

\section{Funding}

The author(s) disclosed receipt of the following financial support for the research, authorship and/or publication of this article: This work was supported by AstraZeneca Spain.

\section{ORCID iD}

Néboa Zozaya iD https://orcid.org/0000-0003-4618-6894

\section{Supplemental material}

Supplemental material for this article is available online.

\section{References}

1. World Health Organization. Global report on diabetes. Geneva: World Health Organization, 2016, p. 86.

2. Crespo C, Brosa M, Soria-Juan A, et al. Costes directos de la diabetes mellitus y de sus complicaciones en España (Estudio SECCAID: Spain estimated cost CiberdemCabimer in diabetes). Adv Diabetología 2013; 29: 182-189.

3. International Diabetes Federation. IDF diabetes atlas. 7th ed. Brussels: International Diabetes Federation, 2015.

4. Ministerio de Sanidad y Consumo. Estrategia en Diabetes del Sistema Nacional de Salud. Madrid: Ministerio de Sanidad y Consumo, 2007.

5. RedGDPS. Práctica clínica en la DM2: Análisis crítico de las evidencias por la RedGDPS. Barcelona: RedGDPS Elsevier Doyma, 2010.

6. American Diabetes Association. Standards of medical care diabetes-2018. Diabetes Care 2018; 41, https://iabetesed .net/wp-content/uploads/2017/12/2018-ADA-Standards-of -Care.pdf

7. Fundación GDPS. Guía de Actualización en Diabetes, 2016, https://www.redgdps.org/guia-de-actualizacion-en-diabetes $-20161005 /$

8. Goring S, Hawkins N, Wygant G, et al. Dapagliflozin compared with other oral anti-diabetes treatments when added to metformin monotherapy: a systematic review and network meta-analysis. Diabetes Obes Metab 2014; 16: 433-442.

9. Lozano-Ortega G, Goring S, Bennett HA, et al. Network meta-analysis of treatments for type 2 diabetes mellitus following failure with metformin plus sulfonylurea. Curr Med Res 2016; 32: 807-816.

10. Inzucci S, Bergenstal R, Buse J, et al. Management of hyperglycemia in type 2 diabetes: a patient-centered approach. Diabetes Care 2012; 35: 1364-1379.

11. Zueger PM, Schultz NM and Lee TA. Cost effectiveness of liraglutide in type II diabetes: a systematic review. Pharmaco Econ 2014; 32: 1079-1091.

12. National Institute for Clinical Excellence (NICE). Algorithm for blood glucose lowering therapy in adults with type 2 diabetes, https://www.nice.org.uk/guidance/ng28/resources /algorithm-for-blood-glucose-lowering-therapy-in-adults -with-type-2-diabetes-2185604173 (2015, accessed 12 October 2018).

13. Garber AJ, Abrahamson MJ, Barzilay JI, et al. Consensus statement by the American Association of Clinical Endocrinologists and American College of Endocrinology on the comprehensive type 2 diabetes management algorithm. Endocr Pract 2018; 24: 91-120.

14. García Ruiz A, Martos F and García-Agua N. Revisión sistemática de evaluaciones económicas de los nuevos medicamentos para el control de la glucosa en diabetes mellitus tipo 2 comercializados en España, http://catsalut .gencat.cat/web/.content/minisite/catsalut/proveidors _professionals/medicaments_farmacia/farmaeconomica /caeip/informes_dictaments/diabetes/diabetes_informe junio2010_es.pdf (2009, accessed 15 December 2018). 
15. Centre for Reviews and Dissemination, University of York. Systematicreviews:CRD'sguidanceforundertakingreviewsin health care, www.york.ac.uk/media/crd/Systematic_Reviews .pdf (2008, accessed 13 January 2018).

16. Eurostat. Euro/ECU exchange rates: annual data. http:// appsso.eurostat.ec.europa.eu/nui/show.do?dataset=ert_bil _eur_a\&lang=en (2019, accessed 25 January 2019).

17. Eurostat. Harmonized index consumer prices $(2015=100)$ : annual data (average index and rate of change), http:// appsso.eurostat.ec.europa.eu/nui/show.do?dataset=prc hicp_aind\&lang=en (2019, accessed 20 March 2019).

18. Vallejo-Torres L, García-Lorenzo B and Serrano-Aguilar P. Estimating a cost-effectiveness threshold for the Spanish NHS. Health Econ 2018; 27: 746-761.

19. Drummond MF and Jefferson TO. Guidelines for authors and peer reviewers of economic submissions to the BMJ: the BMJ Economic Evaluation Working Party. BMJ 1996; 313: 275-283.

20. Kiadaliri AA, Gerdtham UG, Eliasson B, et al. Cost-utility analysis of glucagon-like Peptide-1 agonists compared with dipeptidyl peptidase-4 inhibitors or neutral protamine Hagedorn Basal insulin as add-on to metformin in type 2 diabetes in Sweden. Diabetes Ther 2014; 5: 591-607.

21. Steen Carlsson K and Persson U. Cost-effectiveness of add-on treatments to metformin in a Swedish setting: liraglutide vs sulphonylurea or sitagplitin. J Med Econ 2014; 17: 658-669.

22. Van Haalen HG, Pompen M, Bergenheim K, et al. Cost effectiveness of adding dapagliflozin to insulin for the treatment of type 2 diabetes mellitus in the Netherlands. Clin Drug Invest 2014; 34: 135-146.

23. Ericsson $\AA$ and Lundqvist A. Cost effectiveness of insulin degludec plus liraglutide (IDegLira) in a fixed combination for uncontrolled type 2 diabetes mellitus in Sweden. Appl Health Econ Health Policy 2017; 15: 237-248.

24. Grzeszczak W, Czupryniak L, Kolasa K, et al. The costeffectiveness of saxagliptin versus NPH insulin when used in combination with other oral antidiabetes agents in the treatment of type 2 diabetes mellitus in Poland. Diabetes Technol Ther 2012; 14: 65-73.

25. Hunt B, Glah D and Van der Vliet M. Modeling the longterm cost-effectiveness of IDegLira in patients with type 2 diabetes who are failing to meet glycemic targets on Basal insulin alone in the Netherlands. Diabetes Ther 2017; 8: 753-765.

26. Abad Paniagua EJ, Casado Escribano P, Fernandez Rodriguez JM, et al. [Cost-effectiveness analysis of dapagliflozin compared to DPP4 inhibitors and other oral antidiabetic drugs in the treatment of type- 2 diabetes mellitus in Spain]. Aten Primaria 2015; 47: 505-513.

27. Charokopou M, McEwan P, Lister S, et al. Cost-effectiveness of dapagliflozin versus DPP-4 inhibitors as an add-on to metformin in the treatment of type 2 diabetes mellitus from a UK healthcare system perspective. BMC Health Serv Res 2015; 15: 496 .

28. Tzanetakos C, Tentolouris N, Kourlaba G, et al. Costeffectiveness of dapagliflozin as add-on to metformin for the treatment of type 2 diabetes mellitus in Greece. Clin Drug Invest 2016; 36: 649-659.
29. McEwan P, Gordon J, Evans M, et al. Estimating costeffectiveness in type 2 diabetes: the impact of treatment guidelines and therapy duration. Med Decis Making 2015; 35: 660-670.

30. Charokopou M, McEwan P, Lister S, et al. The costeffectiveness of dapagliflozin versus sulfonylurea as an add-on to metformin in the treatment of type 2 diabetes mellitus. Diabet Med 2015; 32: 890-898.

31. Sabale U, Ekman M, Granstrom O, et al. Cost-effectiveness of dapagliflozin (Forxiga ${ }^{\circledR}$ ) added to metformin compared with sulfonylurea added to metformin in type 2 diabetes in the Nordic countries. Prim Care Diabetes 2015; 9:39-47.

32. McEwan P, Bennett $\mathrm{H}$, Ward $\mathrm{T}$, et al. Refitting of the UKPDS 68 risk equations to contemporary routine clinical practice data in the UK. Pharmaco Econ 2015; 33: 149-161.

33. Vega-Hernandez G, Wojcik R and Schlueter M. Costeffectiveness of liraglutide versus dapagliflozin for the treatment of patients with type 2 diabetes mellitus in the UK. Diabetes Ther 2017; 8: 513-530.

34. Sabapathy S, Neslusan C, Yoong K, et al. Cost-effectiveness of canagliflozin versus sitagliptin when added to metformin and sulfonylurea in type 2 diabetes in Canada. J Popul Ther Clin Pharmacol 2016; 23: e151-e168.

35. Bruhn D, Martin AA, Tavares R, et al. Cost-utility of albiglutide versus insulin lispro, insulin glargine, and sitagliptin for the treatment of type 2 diabetes in the US. $J$ Med Econ 2016; 19: 672-683.

36. Chuang LH, Verheggen BG, Charokopou M, et al. Costeffectiveness analysis of exenatide once-weekly versus dulaglutide, liraglutide, and lixisenatide for the treatment of type 2 diabetes mellitus: an analysis from the UK NHS perspective. J Med Econ 2016; 19: 1127-1134.

37. Tzanetakos C, Melidonis A, Verras C, et al. Costeffectiveness analysis of liraglutide versus sitagliptin or exenatide in patients with inadequately controlled type 2 diabetes on oral antidiabetic drugs in Greece. BMC Health Serv Res 2014; 14: 419.

38. Valentine WJ, Palmer AJ, Lammert M, et al. Evaluating the long-term cost-effectiveness of liraglutide versus exenatide BID in patients with type 2 diabetes who fail to improve with oral antidiabetic agents. Clin Ther 2011; 33: 1698-1712.

39. Hunt B, Ye Q, Valentine WJ, et al. Evaluating the long-term cost-effectiveness of daily administered GLP-1 receptor agonists for the treatment of type 2 diabetes in the United Kingdom. Diabetes Ther 2017; 8: 129-147.

40. Lee WC, Conner C and Hammer M. Results of a model analysis of the cost-effectiveness of liraglutide versus exenatide added to metformin, glimepiride, or both for the treatment of type 2 diabetes in the United States. Clin Ther 2010; 32: 1756-1767.

41. Tzanetakos C, Bargiota A, Kourlaba G, et al. Cost effectiveness of exenatide once weekly versus insulin glargine and liraglutide for the treatment of type 2 diabetes mellitus in Greece. Clin Drug Investig 2017; 38: 67-77.

42. Basson M, Ntais D, Ayyub R, et al. The cost-effectiveness of dulaglutide $1.5 \mathrm{mg}$ versus exenatide $\mathrm{QW}$ for the treatment of patients with type 2 diabetes mellitus in France. Diabetes Ther 2017; 9: 13-25. 
43. Guillermin AL, Lloyd A, Best JH, et al. Long-term costconsequence analysis of exenatide once weekly vs sitagliptin or pioglitazone for the treatment of type 2 diabetes patients in the United States. J Med Econ 2012; 15: 654-663.

44. Sinha A, Rajan M, Hoerger T, et al. Costs and consequences associated with newer medications for glycemic control in type 2 diabetes. Diabetes Care 2010; 33: 695-700.

45. Gaebler JA, Soto-Campos G, Alperin P, et al. Health and economic outcomes for exenatide once weekly, insulin, and pioglitazone therapies in the treatment of type 2 diabetes: a simulation analysis. Vasc Health Risk Manag 2012; 8: 255-264.

46. Dilla T, Alexiou D, Chatzitheofilou I, et al. The costeffectiveness of dulaglutide versus liraglutide for the treatment of type 2 diabetes mellitus in Spain in patients with BMI $\geqslant 30 \mathrm{~kg} / \mathrm{m}^{2}$. J Med Econ 2017; 20: 443-452.

47. Hunt B, Kragh N, McConnachie CC, et al. Long-term cost-effectiveness of two GLP-1 receptor agonists for the treatment of type 2 diabetes mellitus in the Italian setting: liraglutide versus lixisenatide. Clin Ther 2017; 39: 1347-1359.

48. Hunt B, Vega-Hernandez G, Valentine WJ, et al. Evaluation of the long-term cost-effectiveness of liraglutide vs lixisenatide for treatment of type 2 diabetes mellitus in the UK setting. Diabetes Obes Metab 2017; 19: 842-849.

49. Mezquita-Raya P, Ramírez de Arellano A, Kragh N, et al. Liraglutide versus lixisenatide: long-term cost-effectiveness of GLP-1 receptor agonist therapy for the treatment of type 2 diabetes in Spain. Diabetes Ther 2017; 8: 401-415.

50. Roussel R, Martinez L, Vandebrouck T, et al. Evaluation of the long-term cost-effectiveness of liraglutide therapy for patients with type 2 diabetes in France. J Med Econ 2016; 19: 121-134.

51. Perez A, Mezquita R, Ramirez de A, et al. Cost-effectiveness analysis of incretin therapy for type 2 diabetes in Spain: 1.8 mg liraglutide versus sitagliptin. Diabetes Ther 2015; 6: 61-74.

52. Mezquita R, Perez A, Ramirez de A, et al. Incretin therapy for type 2 diabetes in Spain: a cost-effectiveness analysis of liraglutide versus sitagliptin. Diabetes Ther 2013; 4: 417-430.

53. Davies MJ, Chubb BD, Smith IC, et al. Cost-utility analysis of liraglutide compared with sulphonylurea or sitagliptin, all as add-on to metformin monotherapy in type 2 diabetes mellitus. Diabet Med 2011; 29: 313-320.

54. Lee WC, Samyshkin Y, Langer J, et al. Long-term clinical and economic outcomes associated with liraglutide versus sitagliptin therapy when added to metformin in the treatment of type 2 diabetes: a CORE diabetes model analysis. $J$ Med Econ 2012; 15(Suppl. 2): 28-37.

55. Lee WC, Conner C and Hammer M. Cost-effectiveness of liraglutide versus rosiglitazone, both in combination with glimepiride in treatment of type 2 diabetes in the US. Curr Med Res Opin 2011; 27: 897-906.

56. Waugh N, Cummins E, Royle P, et al. Newer agents for blood glucose control in type 2 diabetes: systematic review and economic evaluation. Health Technol Assess 2010; 14: $1-248$.

57. Huetson P, Palmer JL, Levorsen A, et al. Cost-effectiveness of once daily GLP-1 receptor agonist lixisenatide compared to bolus insulin both in combination with basal insulin for the treatment of patients with type 2 diabetes in Norway. $J$ Med Econ 2015; 18: 573-585.

58. Hunt B, Mocarski M, Valentine WJ, et al. Evaluation of the long-term cost-effectiveness of IDegLira versus liraglutide added to basal insulin for patients with type 2 diabetes failing to achieve glycemic control on basal insulin in the USA. J Med Econ 2017; 20: 663-670.

59. Davies MJ, Glah D, Chubb B, et al. Cost effectiveness of IDegLira vs. alternative Basal insulin intensification therapies in patients with type 2 diabetes mellitus uncontrolled on Basal insulin in a UK setting. Pharmaco Econ 2016; 34: 953-966.

60. Kvapil M, Prázný M, Holik P, et al. Cost-effectiveness of IDegLira versus insulin intensification regimens for the treatment of adults with type 2 diabetes in the Czech Republic. Diabetes Ther 2017; 8: 1331-1347.

61. Psota M, Psenkova MB, Racekova N, et al. Costeffectiveness analysis of IDegLira versus Basal-bolus insulin for patients with type 2 diabetes in the Slovak health system. Clinicoecon Outcomes Res 2017; 9: 749-762.

62. Fonseca T, Clegg J, Caputo G, et al. The cost-effectiveness of exenatide once weekly compared with exenatide twice daily and insulin glargine for the treatment of patients with type two diabetes and body mass index $>/=30 \mathrm{~kg} / \mathrm{m}^{2}$ in Spain. J Med Econ 2013; 16: 926-938.

63. Samyshkin Y, Guillermin A, Best J, et al. Long-term costutility analysis of exenatide once weekly versus insulin glargine for the treatment of type 2 diabetes patients in the US (Provisional abstract). J Med Econ 2012; 15(Suppl. 2): 6-13.

64. Beaudet A, Palmer JL, Timlin L, et al. Cost-utility of exenatide once weekly compared with insulin glargine in patients with type 2 diabetes in the UK. J Med Econ 2011; 14: 357-366.

65. Goodall G, Costi M, Timlin L, et al. [Cost-effectiveness of exenatide versus insulin glargine in Spanish patients with obesity and type 2 diabetes mellitus]. Endocrinol Nutr 2011; 58: 331-340.

66. Gordon J, McEwan P, Sabale U, et al. The cost-effectiveness of exenatide twice daily (BID) vs insulin lispro three times daily (TID) as add-on therapy to titrated insulin glargine in patients with type 2 diabetes. J Med Econ 2016; 19: 1167-1174.

67. Langer J, Hunt B and Valentine WJ. Evaluating the shortterm cost-effectiveness of liraglutide versus sitagliptin in patients with type 2 diabetes failing metformin monotherapy in the United States. JMCP 2013; 19: 237-246.

68. Gordon J, McEwan P, Hurst M, et al. The cost-effectiveness of alogliptin versus sulfonylurea as add-on therapy to metformin in patients with uncontrolled type 2 diabetes mellitus. Diabetes Ther 2016; 7: 825-845.

69. McEwan P, Evans M and Bergenheim K. A population model evaluating the costs and benefits associated with different oral treatment strategies in people with type 2 diabetes. Diabetes Obes Metab 2010; 12: 623-630.

70. Gordon J, McEwan P, Evans M, et al. Managing glycaemia in older people with type 2 diabetes: a retrospective, primary care-based cohort study, with economic assessment of patient outcomes. Diabetes Obes Metab 2017; 19: 644-653. 
71. Klarenbach S, Cameron C, Singh S, et al. Cost-effectiveness of second-line antihyperglycemic therapy in patients with type 2 diabetes mellitus inadequately controlled on metformin. CMAJ 2011; 183: E1213-E1220.

72. Kousoulakou H, Hatzikou M, Baroutsou V, et al. Cost effectiveness of vildagliptin versus glimepiride as add-on treatment to metformin for the treatment of diabetes mellitus type 2 patients in Greece. Cost Eff Resour Alloc 2017; 15: 19.

73. Viriato D, Calado F, Gruenberger JB, et al. Costeffectiveness of metformin plus vildagliptin compared with metformin plus sulphonylurea for the treatment of patients with type 2 diabetes mellitus: a Portuguese healthcare system perspective. J Med Econ 2014; 17: 499-507.

74. Granstrom O, Bergenheim K, McEwan P, et al. Costeffectiveness of saxagliptin (Onglyza ${ }^{\mathbb{R}}$ ) in type 2 diabetes in Sweden. Prim Care Diabetes 2012; 6: 127-136.

75. Brown S, Grima D and Sauriol L. Cost-effectiveness of insulin glargine versus sitagliptin in insulin-naive patients with type 2 diabetes mellitus (Provisional abstract). Clin Ther 2014; 36: 1576-1587.

76. Bergenheim K, Williams S, Bergeson J, et al. US costeffectiveness of saxagliptin in type 2 diabetes mellitus. $\mathrm{Am}$ J Pharm Ben 2012; 4: 20-28.

77. Erhardt W, Bergenheim K, Duprat-Lomon I, et al. Cost effectiveness of saxagliptin and metformin versus sulfonylurea and metformin in the treatment of type 2 diabetes mellitus in Germany: a Cardiff diabetes model analysis. Clin Drug Investig 2012; 32: 189-202.

78. Bergenheim K, Williams S, Bergeson J, et al. Costeffectiveness of saxagliptin in type 2 diabetes in the United States. Diabetes 2011; 60: A629-A630.

79. National Institute for Clinical Excellence (NICE). Type 2 diabetes in adults: management - NICE Guideline, 2018, https://www.nice.org.uk/guidance/ng28/resources/type-2 -diabetes-in-adults-management-pdf-1837338615493 (2015, accessed 1 December 2018).

80. National Institute for Clinical Excellence (NICE). Dapagliflozin in combination therapy for treating type 2 diabetes (TA288), https://www.nice.org.uk/guidance/ta288/resources /dapagliflozin-in-combination-therapy-for-treating-type 2 -diabetes-pdf-82600679642821 (2013, accessed 2 January 2019).

81. National Institute for Clinical Excellence (NICE). Canagliflozin in combination therapy for treating type 2 diabetes (TA315), https://www.nice.org.uk/guidance/ta315/ resources/canagliflozin-in-combination-therapy-for-treating- type2-diabetes-pdf-82602428123077 (2014, accessed 3 March 2019).

82. National Institute for Clinical Excellence (NICE). Empagliflozin in combination therapy for treating type 2 diabetes (TA336), https://www.nice.org.uk/guidance /ta336/resources/empagliflozin-in-combination-therapy -for-treating-type2diabetes-pdf-82602550735045 (2015, accessed 3 March 2019).

83. National Institute for Clinical Excellence (NICE). Dapagliflozin in triple therapy for treating type 2 diabetes (TA418), https://www.nice.org.uk/guidance/ta418/resources /dapagliflozin-in-triple-therapy-for-treating-type-2-diabetes -pdf-82604609944261 (2016, accessed 20 January 2019).

84. García-Lorenzo B, Vallejo-Torres L, Trujillo-Martín M, et al. Evaluación económica busca umbral para apoyar la toma de decisiones. Rev Esp Salud Public 2015; 89: 537-544.

85. Lopez JM, Macomson B, Ektare V, et al. Evaluating drug cost per response with SGLT2 inhibitors in patients with type 2 diabetes mellitus. Am Health Drug Benefits 2015; 8: 309-318.

86. Bell CM. Bias in published cost effectiveness studies: systematic review. BMJ 2006; 332: 699-703.

87. Baker CB, Johnsrud MT, Crismon ML, et al. Quantitative analysis of sponsorship bias in economic studies of antidepressants. Br J Psychiatry 2003; 183: 498-506.

88. Higgins JPT, Altman DG, Gotzsche PC, et al. The Cochrane collaboration's tool for assessing risk of bias in randomised trials. BMJ 2011; 343: d5928.

89. European Medicines Agency. SGLT2 inhibitors: information on potential risk of toe amputation to be included in prescribing information, https://www.ema.europa.eu/en /medicines/human/referrals/sglt2-inhibitors-previously -canagliflozin (2017, accessed 15 December 2018).

90. US Food and Drug Administration. FDA Drug Safety Communication: FDA revises label of diabetes drug canagliflozin (Invokana, Invokamet) to include updates on bone fracture risk and new information on decreased bone mineral density, https://www.fda.gov/drugs/drug -safety-and-availability/fda-drug-safety-communication -fda-revises-label-diabetes-drug-canagliflozin-invokana -invokamet (2015, accessed 15 December 2018).

91. AEMPS. Canagliflozina y riesgo de amputación no traumatic en miembros inferiores, https://www.aemps.gob .es/informa/notasInformativas/medicamentosUsoHumano /seguridad/2017/docs/NI-MUH_FV_01-canagliflozina.pdf (2017, accessed 20 December 2018). 